\title{
Resetting chemical clocks of hot cores based on S-bearing molecules ${ }^{\star}$
}

\author{
V. Wakelam ${ }^{1}$, P. Caselli ${ }^{2}$, C. Ceccarelli ${ }^{3}$, E. Herbst ${ }^{4}$, and A. Castets ${ }^{1}$ \\ 1 Observatoire de Bordeaux, BP 89, 33270 Floirac, France \\ 2 INAF-Osservatorio Astrofisico di Arcetri, Largo E. Fermi 5, 50125 Firenze, Italy \\ 3 Laboratoire d'Astrophysique, Observatoire de Grenoble, BP 53, 38041 Grenoble cedex 09, France \\ ${ }^{4}$ Departments of Physics, Chemistry, and Astronomy, The Ohio State University, Columbus, OH 43210, USA
}

Received 2 February 2004 / Accepted 7 April 2004

\begin{abstract}
We report a theoretical study of sulphur chemistry, as applied to hot cores, where S-bearing molecular ratios have been previously proposed and used as chemical clocks. As in previous models, we follow the S-bearing molecular composition after the injection of grain mantle components into the gas phase. For this study, we developed a time-dependent chemical model with up-to-date reaction rate coefficients. We ran several cases, using different realistic chemical compositions for the grain mantles and for the gas prior to mantle evaporation. The modeling shows that S-bearing molecular ratios depend very critically on the gas temperature and density, the abundance of atomic oxygen, and, most importantly, on the form of sulphur injected in the gas phase, which is very poorly known. Consequently, ratios of S-bearing molecules cannot be easily used as chemical clocks. However, detailed observations and careful modeling of both physical and chemical structure can give hints on the source age and constrain the mantle composition (i.e. the form of sulphur in cold molecular clouds) and, thus, help to solve the mystery of the sulphur depletion. We analyse in detail the cases of Orion and IRAS 16293-2422. The comparison of the available observations with our model suggests that the majority of sulphur released from the mantles is mainly in, or soon converted into, atomic form.
\end{abstract}

Key words. ISM: abundances - ISM: molecules - stars: formation - astrochemistry

\section{Introduction}

It is a long-standing dream to use relative abundances of different molecules as chemical clocks to measure the ages of astronomical objects. Studies of the ages of star formation regions have recently focused on S-bearing molecules. Charnley (1997) and Hatchell et al. (1998) were the first to propose that the relative abundance ratios of $\mathrm{SO}, \mathrm{SO}_{2}$ and $\mathrm{H}_{2} \mathrm{~S}$ could be used to estimate the age of the hot cores of massive protostars. The underlying idea is that the main reservoir of sulphur is $\mathrm{H}_{2} \mathrm{~S}$ on grain mantles, and that when the hot core forms, the mantles evaporate, injecting the hydrogen sulphide into the gas phase. Endothermic reactions in the hot gas convert $\mathrm{H}_{2} \mathrm{~S}$ into atomic sulphur and $\mathrm{SO}$ from which more $\mathrm{SO}$ and, subsequently, $\mathrm{SO}_{2}$ are formed, making the $\mathrm{SO}_{2} / \mathrm{SO}$ and $\mathrm{SO} / \mathrm{H}_{2} \mathrm{~S}$ ratios nice functions of time. These studies have triggered a variety of work, both observational and theoretical (Charnley 1997; Hatchell et al. 1998; Buckle \& Fuller 2003).

Send offprint requests to: V. Wakelam,

e-mail: wakelam@obs.u-bordeaux1.fr

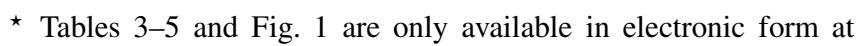
http://www. edpsciences.org
This line of research, however, has been challenged by recent ISO observations, which have cast doubt on the basic assumption that sulphur is mainly trapped in grain mantles as $\mathrm{H}_{2} \mathrm{~S}$. The lack of an appropriate feature in the ISO spectra of high (Gibb et al. 2000) and low (Boogert et al. 2000) mass protostars sets an upper limit on the mantle $\mathrm{H}_{2} \mathrm{~S}$ abundance which cannot exceed about $10^{-7}$ with respect to $\mathrm{H}_{2}$ (van Dishoeck \& Blake 1998). Indeed, the identity of the major reservoir of sulphur in cold molecular clouds is a long standing and unresolved problem, for the sum of the detectable S-bearing molecules is only a very small fraction of the elemental $\mathrm{S}$ abundance (Tieftrunk et al. 1994). Since sulphur is known not to be depleted in the diffuse medium (e.g. Sofia et al. 1994), it is usually assumed that sulphur in dense clouds is depleted onto the grain mantles rather than in refractory cores (e.g. Caselli et al. 1994), but how this happens is a mystery. In a theoretical study, Ruffle et al. (1999) proposed that in collapsing translucent clouds sulphur is efficiently adsorbed onto grain mantles. In fact, in these regions, most of the gas-phase sulphur is in the form of $\mathrm{S}^{+}$, while grains are typically negatively charged, so that the collisional cross section for sulphur is enhanced compared with neutral species (e.g. O) and sulphur is removed from the gas phase more rapidly. 
Another mystery is the form of sulphur on dust grains. The simplest possibility is that it consists of relatively isolated atoms, as would occur in a matrix, or perhaps as isolated pairs of atoms $\left(\mathrm{S}_{2}\right)$. Another possibility is that the sulphur is amorphous (or even crystalline), having formed islands of material from the initially adsorbed atoms. Crystalline sulphur is known to come in two forms - rhombic and monoclinic - both of which consist of $S_{8}$ cyclic molecules. Vaporization leads to a complex mixture of sulfur polymers through $\mathrm{S}_{8}$ in complexity. If sulphur is elemental and amorphous, evaporation is also likely to lead to molecules of sulphur through eight atoms in complexity. So far, the only S-bearing species firmly detected on granular surfaces is OCS, but with a relatively low fractional abundance of $10^{-7}$ (Palumbo et al. 1997). Recently, Keller et al. (2002) claimed the detection of iron sulphide (FeS) grains in protoplanetary disks, but there is no evidence to suggest that solid FeS is the main form of sulphur in the parent collapsing environment. Actually, if the main form of solid sulphur is FeS, $\mathrm{S}$ should follow Fe depletion, which is not observed (Sofia et al. 1994). Even more recently, Scappini et al. (2003) suggested that hydrated sulphuric acid $\left(\mathrm{H}_{2} \mathrm{SO}_{4} \cdot \mathrm{H}_{2} \mathrm{O}\right)$ is the main sulphur reservoir. In whatever form sulphur resides in the grain mantles, there is the possibility that the species, once evaporated, are very quickly destroyed to give atomic sulphur. In summary, although all the evidence is that sulphur is depleted onto grain mantles in cold clouds, its particular form is very uncertain.

Given the need for chemical clock methods, it is timely to reconsider the use of S-bearing molecules in this fashion. In this paper, we present a model with an up-to-date chemical network involving S-bearing molecules. We run several cases to cover a large, realistic parameter space for hot core sources, consistent with present observational constraints. Based on the results we obtain, we conclude that it is tricky to use abundance ratios of S-bearing molecules as chemical clocks in the absence of other constraints, for they depend more on the initial conditions, gas density, temperature, and the initial form of sulphur injected in the gas phase than on the age of the source.

The paper is organized as follows: we describe the model in Sect. 2, the model results in Sect. 3, and in Sect. 4 we discuss the practical consequences of those results and apply the model to the specific cases of Orion and IRAS 16293-2422.

\section{The model}

We have developed a pseudo-time dependent model for the gas phase chemistry that computes the evolution of the chemical composition of a volume of gas with a fixed density and temperature. Our goal is to follow how the S-bearing molecular abundances vary with time when the gas undergoes a sudden change in its temperature and density, and/or in its overall chemical abundance, because of the evaporation of grain mantles. In hot cores the dust temperature increases to an extent that it exceeds the mantle evaporation temperature, i.e. $\sim 100 \mathrm{~K}$, and all the components of the grain mantles are suddenly injected into the gas phase, similarly to what has been done in previous studies of hot cores (e.g. Brown et al. 1988; Charnley et al. 1992; Caselli et al. 1993; Millar et al. 1997b). In fact, it is more probable that hot cores have spatial gradients in temperature and density releasing the molecules at different times depending on their surface binding energies (see Ceccarelli et al. 1996; Viti \& Williams 1999; Doty et al. 2002; Rodgers \& Charnley 2003). However, the goal of this work is mainly to test the effects of the form of the main initial sulphur bearing molecules and we preferred to simplify the problem assuming that all the molecules evaporate simultaneously from the grain. More detailed models will be presented in a forthcoming paper.

In order to simulate these conditions, the gas-phase chemical composition prior to evaporation of the mantles is taken to be similar to that of dark molecular clouds. At time $t=0$, the grain mantle components are injected into the gas phase, and the model follows the changes in the gas chemical composition with a given gas temperature and density. Throughout this paper we will use the word "evaporation" to refer to the loss of the grain mantles.

The model is a reduced chemical network, which includes 930 reactions involving 77 species containing the elements $\mathrm{H}, \mathrm{He}, \mathrm{C}, \mathrm{O}$ and $\mathrm{S}$. The standard neutral-neutral and ion-neutral reactions are considered. Most of the reaction coefficients are from the NSM ("new standard model"; http://www . physics.ohio-state.edu/ eric/ research_files/cddata.july03) database; see also Lee et al. (1996), updated with new values or new analyses of assorted values in databases (e.g. the NIST chemical kinetics database at http://kinetics.nist.gov/index.php) when available. Furthermore, several high temperature (neutral-neutral) reactions have been added. To select the reduced network, we have followed Ruffle et al. (2002) for CO formation, Hollenbach \& McKee (1979) and Hartquist et al. (1980) for the oxygen chemistry and Pineau Des Forêts et al. (1993) and Charnley (1997) for the sulphur chemistry.

To validate this network, we compared our results with abundances previously obtained by Lee et al. (1996) at low temperature and Charnley (1997) at higher temperatures using the same initial abundances as these authors. We found that we can reproduce molecular abundances to better than a factor of three. This is an indication that small variations in the rate coefficients between the updated NSM and UMIST databases do not strongly influence the computed abundances of sulphur bearing species. One exception is the CS molecule, which we produce at an abundance ten times less than Charnley's model, because our adopted rate coefficient for the reaction $\mathrm{CO}+\mathrm{CRPHOT} \rightarrow \mathrm{O}+\mathrm{C}$, (where CRPHOT is a photon induced by cosmic rays) is 50 times smaller than in the UMIST database. The lowered abundance of $\mathrm{C}$ then translates into a lowered abundance for CS, since $\mathrm{C}$ is a precursor of CS.

Note that we have assumed the gas to be totally shielded from the interstellar UV field and no other UV field to be present. Thus, the model does not include any photochemistry, with the exception of cosmic ray-induced photodestruction reactions. The model takes into account a reduced gas-grain chemistry: $\mathrm{H}_{2}$ is formed on grain surfaces and the recombination of ions with negatively charged grains occurs (see Aikawa et al. 1999, for the recombination of ions with negative grains). Moreover, neutral species can deplete onto grain mantles, and 
mantle molecules can evaporate because of thermal effects and cosmic rays (Hasegawa et al. 1992; Hasegawa \& Herbst 1993).

\subsection{Gas-phase and mantle abundances prior to evaporation}

To help determine a set of molecular abundances prior to mantle evaporation, we ran the model with a temperature equal to $10 \mathrm{~K}$ and a density $n_{\mathrm{H}_{2}}$ equal to $10^{4} \mathrm{~cm}^{-3}$, including freeze out, for $10^{7} \mathrm{yr}$. At this time, species such as SO, $\mathrm{SO}_{2}$, and $\mathrm{CS}$ reach abundances similar to those observed in dark clouds $\left(\sim 10^{-9}, \leq 10^{-9}\right.$, and $\sim 10^{-9}$, respectively; Dickens et al. 2000). The adopted elemental abundances (with respect to $\mathrm{H}_{2}$ ) for $\mathrm{He}, \mathrm{O}, \mathrm{C}^{+}$and $\mathrm{S}^{+}$are respectively: $0.28,6.38 \times 10^{-4}$ (Meyer et al. 1998), $2.8 \times 10^{-4}$ (Cardelli et al. 1996) and $0.3 \times 10^{-4}$; the sulphur abundance refers to the gaseous and grain portions (see below). The late-time abundances obtained could not be reasonably used without modification for the preevaporated chemical composition for several reasons. First, our model, like most other gas-phase treatments (e.g. Lee et al. 1996; Millar et al. 1997a), overestimates the $\mathrm{O}_{2}$ and $\mathrm{H}_{2} \mathrm{O}$ abundances in cold dense clouds by orders of magnitude with respect to the ISO, SWAS and ODIN observations (e.g. Bergin et al. 2003; Pagani et al. 2003). Secondly, the elemental sulphur abundance pertaining to the gas must be lowered to avoid getting very high abundances of sulphur-bearing species. The portion of the abundance not used for the gas can be considered to reside in grain mantles until evaporation or in grain core. In order to mimic realistic conditions, we thus adopted three different compositions for the pre-evaporative gas, as follows:

Composition A: we adopted the computed late-time molecular abundances except for $\mathrm{O}_{2}$ and $\mathrm{H}_{2} \mathrm{O}$, which were assumed to be $10^{-7}$ and $10^{-8}$ with respect to $\mathrm{H}_{2}$ respectively, in agreement with observations in molecular clouds, and for atomic oxygen, $\mathrm{O}$, which was assumed to carry the oxygen not locked into $\mathrm{CO}$, leading to a fractional abundance of $2.6 \times 10^{-4}$, as suggested by observations (e.g. Baluteau et al. 1997; Caux et al. 1999; Vastel et al. 2002; Lis et al. 2001). In addition, the initial gas-phase sulphur abundance was taken to be a factor of 30 lower than the elemental abundance.

Composition B: we re-computed the late time abundances, lowering artificially by two orders of magnitude the rate of the dissociative recombination of $\mathrm{H}_{3} \mathrm{O}^{+}$, to decrease the computed $\mathrm{O}_{2}$ and $\mathrm{H}_{2} \mathrm{O}$ abundances. In this case, it was only necessary to lower the initial elemental sulphur abundance by a factor of five. The abundance of atomic oxygen in this case is $4.8 \times 10^{-4}$, consistent with observations in molecular clouds.

Composition $C$ : the abundances were taken to equal those measured in the direction of L134N, as reported in Table 4 of Charnley et al. (2001). The oxygen not contained in the species reported in Table 4 was assumed to be in atomic form.

All three gas-phase compositions have large abundances of atomic oxygen, in agreement with observations. We assume that this large $\mathrm{O}$ abundance is also present at the beginning of the hot core phase, in contrast with previous studies. This implies many differences in the computed abundances, as shown in Sect. 3.1 and discussed in Sect. 4.1. Table 1 lists the
Table 1. Computed late time (A, B) and adopted (C) gas-phase abundances with respect to $\mathrm{H}_{2}$ for the main $\mathrm{S}$-bearing molecules prior to mantle evaporation.

\begin{tabular}{l|c|c|c}
\hline \hline Species & A & B & C \\
\hline $\mathrm{SO}$ & $9 \times 10^{-9}$ & $3 \times 10^{-9}$ & $3.1 \times 10^{-9}$ \\
$\mathrm{SO}_{2}$ & $4 \times 10^{-10}$ & $1.5 \times 10^{-10}$ & $1 \times 10^{-9 a}$ \\
$\mathrm{H}_{2} \mathrm{~S}$ & $1 \times 10^{-10}$ & $1 \times 10^{-11}$ & $8 \times 10^{-10}$ \\
$\mathrm{CS}$ & $4 \times 10^{-10}$ & $2 \times 10^{-8}$ & $1.7 \times 10^{-9}$ \\
\hline
\end{tabular}

${ }^{a}$ Here we took the value of the upper limit.

Table 2. Adopted abundances for mixtures of evaporated S-bearing molecules (with respect to $\mathrm{H}_{2}$ ).

\begin{tabular}{l|cccc}
\hline \hline Species & Mod. 1 & Mod. 2 & Mod. 3 & Mod. 4 \\
\hline OCS & $10^{-7}$ & $10^{-7}$ & $10^{-7}$ & $10^{-7}$ \\
$\mathrm{H}_{2} \mathrm{~S}$ & $10^{-7}$ & $10^{-7}$ & $10^{-7}$ & $10^{-8}$ \\
$\mathrm{~S}$ & 0 & $3 \times 10^{-5}$ & 0 & $3 \times 10^{-5}$ \\
$\mathrm{~S}_{2}$ & 0 & 0 & $1.5 \times 10^{-5}$ & 0 \\
\hline
\end{tabular}

abundances of the main S-bearing molecules for the three gasphase compositions prior to mantle evaporation.

At time $t=0$, the grain mantle components are injected into the gas phase. The abundances of the major mantle components are relatively well constrained by the observations and we took the observed abundances (with respect to $\mathrm{H}_{2}$ ) in high mass protostars: $\mathrm{H}_{2} \mathrm{O}: 10^{-4}$ (Schutte et al. 1996), $\mathrm{H}_{2} \mathrm{CO}: 4 \times 10^{-6}$ (Keane et al. 2001), $\mathrm{CH}_{3} \mathrm{OH}: 4 \times 10^{-6}$ (Chiar et al. 1996) and $\mathrm{CH}_{4}: 10^{-6}$ (Boogert et al. 1998). Note that in order to shorten the number of treated species, we negleted the $\mathrm{CO}_{2}$ molecule which is abundant in mantles $\left(2 \times 10^{-5}\right.$ with respect to $\mathrm{H}_{2}$, Gerakines et al. 1999), because it is not a crucial element of the sulphur chemistry. On the contrary, the situation is very uncertain with respect to the S-bearing mantle molecules, as discussed in the Introduction. In order to study the influence of the injected S-bearing abundances on the evolution of the chemical composition, we have run models with four types of material evaporating from mantles that differ in their major sulphur-bearing species, as reported in Table 2. In practice, sulphur on the grain mantles can be stored as OCS, $\mathrm{H}_{2} \mathrm{~S}$, or pure sulphur in a matrixlike, amorphous, or even crystalline form. Of the four mixtures, the first one (used in model 1) has the bulk of the sulphur in the refractory core of the grain, while the other three (used in models 2-4) have large abundances of elemental sulphur leading upon evaporation directly or eventually to either $S$ or $S_{2}$ in the gas.

\section{2. "Important" reactions}

As the post-evaporative gas-phase chemistry proceeds, it is important to determine the reactions that will influence the formation and destruction of sulphur-bearing species the most severely. We will call them "important" reactions in the following discussion. By this term, we mean quantitatively those reactions that lead to significant variations of the main S-bearing 
abundances when the relevant reaction rate is changed by a small amount (specifically 10\%). Although such a determination has not been featured in papers on astrochemistry, we thought it worthwhile to introduce a suitable procedure here. The aim of this study is twofold: (i) to determine a set of reactions to check carefully in laboratory experiments because the computed abundances are particularly sensitive to those reactions; and (ii) to ascertain whether different chemical networks will lead to different results, and why. To identify these reactions, we first defined a "perturbation" in the rate coefficient for each of the 750 gas-phase reactions by multiplying them by a factor of 1.1, one at a time. For each single perturbation, we then computed the abundance "variations" $\Delta X$ by comparing the computed abundances after $10^{4} \mathrm{yr}$ with the reference abundances calculated with the non-modified set of reaction rates, according to the expression $\Delta X=\frac{\left|X_{\text {ref }}-X\right|}{X_{\text {ref }}}$, where $X_{\text {ref }}$ is the reference abundance and $X$ the abundance obtained with the perturbed rate.

Figure 1 shows the variations of the abundances of the main $\mathrm{S}$-bearing species $\mathrm{H}_{2} \mathrm{~S}, \mathrm{CS}$, and $\mathrm{SO}$ divided by the amplitude of the perturbation $(\Delta R=0.1)$ for a temperature of $100 \mathrm{~K}$ and a density of $10^{7} \mathrm{~cm}^{-3}$. The calculation has been performed for composition A and model 2. The abscissa consists of the numbers of reactions in our network from 86 to 834 . Vertical lines are included for those reactions that produce a normalized variation larger than $1 \%$ of the largest variation, while the actual numbers of reactions with a normalized variation greater than $5 \%$ are listed. Note that for a variation (0.1) equal in size to the amplitude of the perturbation, the line extends upward to unity and that a $\Delta X / \Delta R$ of 0.5 implies that the abundance of the studied molecule change by $5 \%$ in abundance upon a $10 \%$ change in the reaction rate. The sets of numbered "important" reactions for the molecules $\mathrm{H}_{2} \mathrm{~S}, \mathrm{CS}$, and SO consist of 28, 24, and 17 reactions, respectively. We do not show the variations of OCS and $\mathrm{SO}_{2}$ because the OCS abundance is only affected significantly (9\%) if reaction 757 is perturbed, while $\mathrm{SO}_{2}$ shows the same behavior as $\mathrm{SO}$ so the corresponding figure is the same.

In Table 3, we list the 70 most important reactions for the chemistry of $\mathrm{H}_{2} \mathrm{~S}, \mathrm{CS}, \mathrm{SO}, \mathrm{SO}_{2}$ and OCS for initial composition $\mathrm{A}$ and the four models (see previous section) at a temperature of $100 \mathrm{~K}$ and a density of $10^{7} \mathrm{~cm}^{-3}$. The first two columns give the number of the reaction and the actual reaction, while the third column gives the reaction rate coefficient $k$ in terms of the standard parameters $\alpha\left(\mathrm{cm}^{3} \mathrm{~s}^{-1}\right), \beta$ and $\gamma(\mathrm{K})$ :

$$
k=\alpha(T / 300)^{\beta} \exp (-\gamma / T)
$$

where $T$ is the gas temperature. In this table, we report only the rate coefficients that differ by more than $10 \%$ from the UMIST ones. In the last four columns, the symbol • indicates that the reaction is important for sulphur chemistry in the model of the corresponding column. The list of reactions in Table 3 depends only weakly on the choice of initial composition mentioned in Sect. 2.1, because the three initial compositions A, B and $\mathrm{C}$ give sufficiently similar abundances at $10^{4} \mathrm{yr}$.

Of course, for very different initial compositions, the list of important reactions could be slightly different, especially if the network is different. This is for example the case of the
Charnley (1997) model, where all reactions involving atomic oxygen are not important, for no initial gaseous atomic oxygen is assumed to be present, whereas ion-molecule reactions involving molecular ions such as $\mathrm{H}_{3}^{+}, \mathrm{H}_{3} \mathrm{O}^{+}$, and $\mathrm{H}_{3} \mathrm{CO}^{+}$, are crucial.

We found that the relative importance of the reactions in Table 3 depends more on the initial mantle composition (model 1 to 4 ) than on the pre-evaporation composition of the gas (A, B or C). For model 1, the chemical network is simpler (i.e. fewer important reactions) than for models 2, 3, and 4 because there is no initial $S$ or $S_{2}$, so that many reactions forming $\mathrm{CS}$ as well as reactions with $\mathrm{S}$ and $\mathrm{S}^{+}$lose importance. Models 2 and 3 have a similar list of important reactions but some reactions with SO gain in importance for model 3. Models 2 and 4 are even more similar in their lists of important reactions. A few reactions with $\mathrm{H}_{2} \mathrm{~S}$ become less important for model 4 because the initial abundance of $\mathrm{H}_{2} \mathrm{~S}$ in this model is ten times less than in model 2 and only one reaction (number 550) becomes important.

The above analysis of "important" reactions refers to only one perturbation amplitude. In general, since the equations are not linear, the amplitude of the perturbation may influence the results in a non-linear way. To check for non-linearity, we also ran the case where each reaction rate is twice as large as the "standard" one (i.e. a pertubation amplitude of 1.0, which doubles the rate of reaction), and still obtained linear variations, so that normalized variations are independent of amplitude. One exception concerns CS, for which several reactions become important in the latter case. These reactions, listed in Table 4 for composition A and model 2, must be added to the ones shown in Fig. 1 for CS.

Because rate coefficients are often dependent on the temperature, a change in this parameter can affect which reactions are important. In particular, an increase of the temperature to $200 \mathrm{~K}$ makes some of the neutral-neutral reactions more important (Table 5) and some reactions $(579,789,798,800$, 804 and 825) of Table 3 negligible. On the contrary, an increase of the $\mathrm{H}_{2}$ density to $10^{8} \mathrm{~cm}^{-3}$ does not change the results significantly.

Finally, from Tables 3 and 5 and Fig. 1, we can determine the reactions producing the largest variations for the S-bearing species under a set of relevant conditions and a reasonable time $\left(10^{4} \mathrm{yr}\right)$ for our models: reactions $90,153,190,191$, 740,756 and 757. Reaction 90 is the cosmic ray ionization rate of $\mathrm{H}_{2}$, which is obviously important for starting the ionmolecule chemistry. Reactions 153 and 190 are neutral-neutral reactions important only at the higher temperature considered $(200 \mathrm{~K})$. The other reactions (cf. Table 3 ) are a collection of ion-molecule (740), neutral-neutral (191), and radiative association (756 and 757) processes. The importance of these reactions would probably have been overlooked had this analysis not been done. It will therefore be crucial to know the rate coefficients of the mentioned reactions with high precision. Of these reactions, only the rate coefficient for 153 is well determined in the laboratory, although the lowest measured temperature $(300 \mathrm{~K})$ means that the rate coefficient in the 100-200 K range involves an extrapolation. Uncertain measured activation energies for reactions 190 and 191 also lead to 


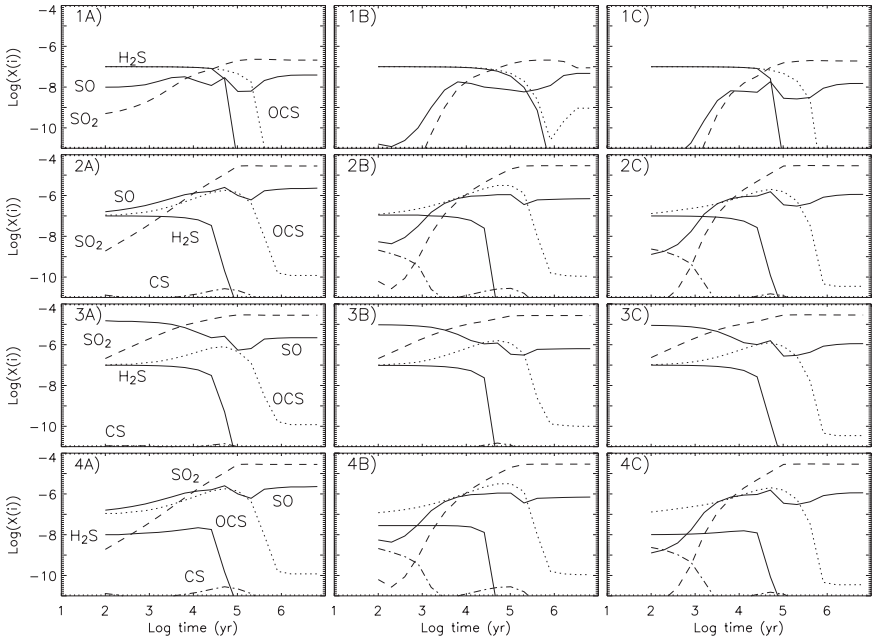

Fig. 2. Evolution of the $\mathrm{SO}_{2}, \mathrm{SO}, \mathrm{H}_{2} \mathrm{~S}$, OCS and $\mathrm{CS}$ abundances with respect to $\mathrm{H}_{2}$ as a function of time, for the three pre-evaporation gas phase compositions A (left panels), B (central panels), and C (right panels) and the four grain mantle compositions ( 1 to 4 , from the top to the bottom). The gas temperature is $100 \mathrm{~K}$ and the $\mathrm{H}_{2}$ density is $10^{7} \mathrm{~cm}^{-3}$.

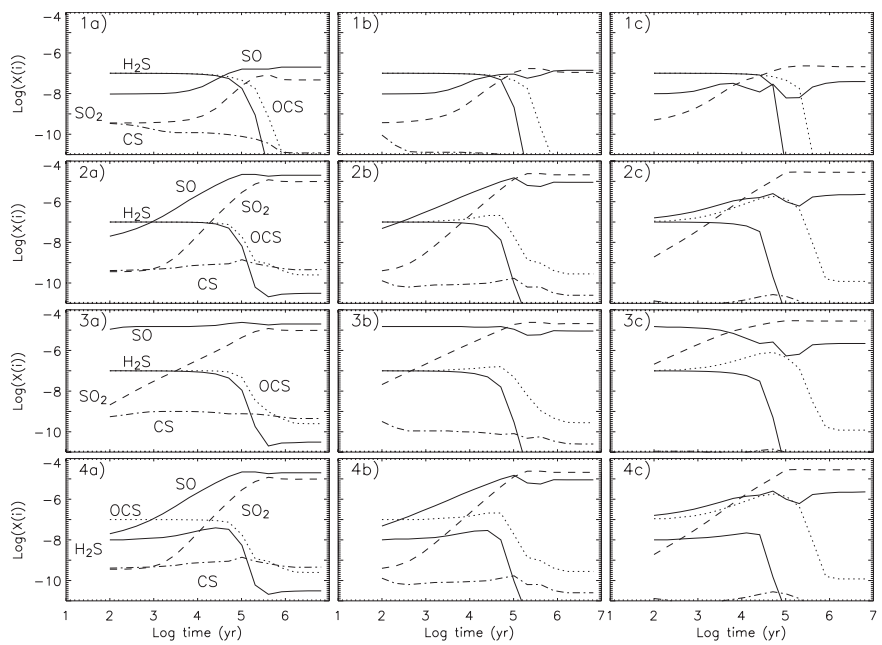

Fig. 3. Evolution of the $\mathrm{SO}_{2}, \mathrm{SO}, \mathrm{H}_{2} \mathrm{~S}$, OCS and $\mathrm{CS}$ abundances with respect to $\mathrm{H}_{2}$ as a function of time, using pre-evaporated gas phase composition $\mathrm{A}$ and the four grain mantle mixtures (1 to 4 , from the top to the bottom). The gas temperature is $100 \mathrm{~K}$ and the density is $10^{5} \mathrm{~cm}^{-3}$ (a) left panels), $10^{6} \mathrm{~cm}^{-3}$ (b) central panels) and $10^{7} \mathrm{~cm}^{-3}$ (c) right panels).

poorly determined rate coefficients by $100-200 \mathrm{~K}$. The ionmolecule reaction (740) may not even be exothermic, while the rate coefficients for the radiative association processes are order-of-magnitude estimates at best.

\section{Results}

\subsection{Abundances with respect to $\mathrm{H}_{2}$}

We have run the four models listed in Table 2, each with the three different gas-phase compositions (A, B, and $\mathrm{C}$ ) prior to evaporation, for gases with temperatures of $100 \mathrm{~K}$ and $300 \mathrm{~K}$, and densities of $10^{5} \mathrm{~cm}^{-3}, 10^{6} \mathrm{~cm}^{-3}$ and $10^{7} \mathrm{~cm}^{-3}$. In this

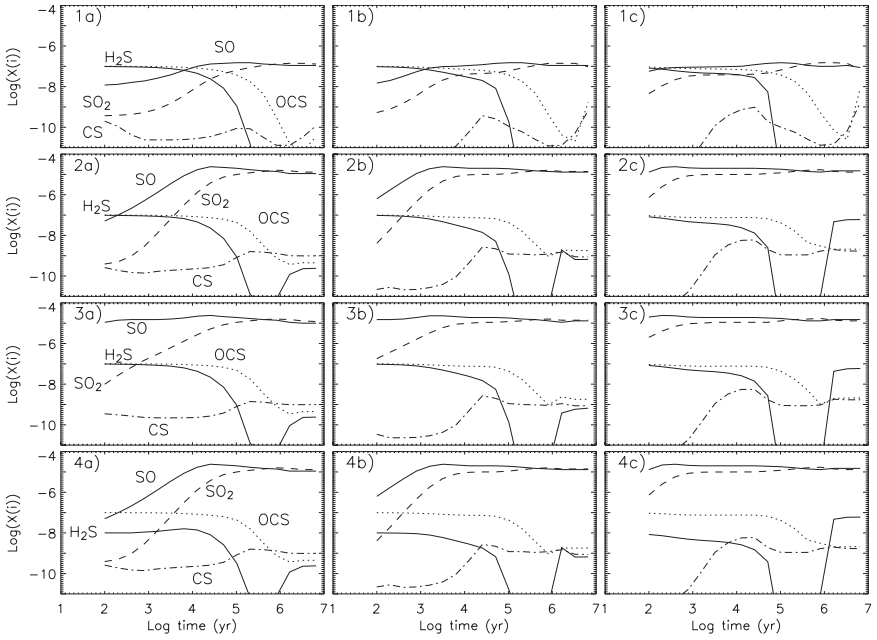

Fig. 4. Same as Fig. 3 but with a temperature of $300 \mathrm{~K}$.

section, we give some sense of the major features of the chemistry of the sulphur-bearing species.

Figure 2 shows the evolution of the abundances of the $\mathrm{SO}_{2}$, $\mathrm{SO}, \mathrm{H}_{2} \mathrm{~S}$, OCS and CS molecules, with respect to $\mathrm{H}_{2}$, for the four models and three gas-phase compositions (with $T=100 \mathrm{~K}$ and $\left.n\left(\mathrm{H}_{2}\right)=10^{7} \mathrm{~cm}^{-3}\right)$. There are clearly differences among the models, at times earlier than $10^{4} \mathrm{yr}$, due to the different initial compositions whereas after $10^{4} \mathrm{yr}$ the three gas phase compositions give similar results. For example, for models 1,2 and 4, the compositions $\mathrm{B}$ and $\mathrm{C}$ give lower $\mathrm{SO}$ and $\mathrm{SO}_{2}$ abundances than the composition $\mathrm{A}$ at times earlier than $10^{4} \mathrm{yr}$, whereas the three gas phase compositions give similar results for model 3. For sake of simplicity, in the following, we will discuss composition $\mathrm{A}$, but the results do not change qualitatively assuming the $\mathrm{B}$ or $\mathrm{C}$ compositions.

Figures 3 and 4 show the evolution, at $100 \mathrm{~K}$ and $300 \mathrm{~K}$ respectively, of the abundances of the main S-bearing species for the four grain mantle compositions of Table 2 at the three different densities. In all the models depicted, $\mathrm{SO}$ and $\mathrm{SO}_{2}$ are the most abundant species at late times. The final large amounts of $\mathrm{SO}_{2}$ are more noticeable in models 2-4, where large amounts of gaseous sulphur are available. At a temperature of $100 \mathrm{~K}$ and a density between $10^{6}$ and $10^{7} \mathrm{~cm}^{-3}$, the $\mathrm{SO}_{2}$ molecule becomes more abundant than $\mathrm{SO}$ after $10^{4}-10^{5} \mathrm{yr}$, mainly because of the neutral-neutral reaction $\mathrm{O}+\mathrm{SO} \rightarrow \mathrm{SO}_{2}+$ photon. Note that this radiative association reaction is critical because of the high abundance of atomic $\mathrm{O}$ in the pre-evaporative gas. At $300 \mathrm{~K}$, the $\mathrm{SO}_{2}$ molecule is formed less efficiently via this mechanism since it possesses an inverse dependence on temperature (see Table 3, reaction 756) but it is still as abundant as SO after $2 \times 10^{5} \mathrm{yr}$ for a density of $10^{5} \mathrm{~cm}^{-3}$, and after $10^{3} \mathrm{yr}$ for a density of $10^{7} \mathrm{~cm}^{-3}$ (see Fig. 4). At $300 \mathrm{~K}, \mathrm{OH}$ is quickly $\left(\leq 10^{2} \mathrm{yr}\right)$ formed through the reaction $\mathrm{H}_{2}+\mathrm{O} \rightarrow \mathrm{OH}+\mathrm{H}$ so that $\mathrm{SO}_{2}$ can be formed by the reaction $\mathrm{OH}+\mathrm{SO} \rightarrow \mathrm{SO}_{2}+\mathrm{H}$. Here, the presence of a large atomic oxygen abundance in the pre-evaporated gas-phase is crucial to produce the high abundance of $\mathrm{OH}$ at early times, contrary to what was found in previous models (e.g. Charnley 1997). In model 3, where the initial sulphur is mostly in $S_{2}$, the 
SO molecule is very quickly $\left(\leq 10^{2} \mathrm{yr}\right)$ formed, as $\mathrm{S}_{2}$ directly leads to $\mathrm{SO}$ through the reaction $\mathrm{S}_{2}+\mathrm{O} \rightarrow \mathrm{SO}+\mathrm{S}$.

Now, let us look at the chemistry of hydrogen sulphide, OCS, and CS. The initial $\mathrm{H}_{2} \mathrm{~S}$ abundance (see Table 2), dips sharply after $10^{4} \mathrm{yr}$ in all models but increases after $10^{6} \mathrm{yr}$ for models 2 to 4 at $300 \mathrm{~K}$. The decrease of the $\mathrm{H}_{2} \mathrm{~S}$ abundance at $10^{4} \mathrm{yr}$ is produced by the attack on $\mathrm{H}_{2} \mathrm{~S}$ by $\mathrm{H}_{3} \mathrm{O}^{+}$, more abundant than $\mathrm{H}_{3}^{+}$in regions, such as hot cores, where water has a large abundance. The reaction between $\mathrm{H}_{3} \mathrm{O}^{+}$and $\mathrm{H}_{2} \mathrm{~S}$ yields protonated hydrogen sulphide $\left(\mathrm{H}_{3} \mathrm{~S}^{+}\right)$, which dissociatively recombines with electrons to form HS at least part of the time: $\mathrm{H}_{3} \mathrm{~S}^{+}+\mathrm{e}^{-} \rightarrow \mathrm{HS}+\mathrm{H}+\mathrm{H}$. The HS product is itself depleted by the reaction $\mathrm{HS}+\mathrm{O} \rightarrow \mathrm{SO}+\mathrm{H}$. At $300 \mathrm{~K}, \mathrm{H}_{2} \mathrm{~S}$ is efficiently formed at later times $\left(\geq 10^{5} \mathrm{yr}\right)$ by a series of reactions that starts with the destruction by cosmic ray-induced photons of $\mathrm{SO}$ and $\mathrm{SO}^{+}$to produce atomic sulphur. Atomic sulphur is then hydrogenated into HS first, and then $\mathrm{H}_{2} \mathrm{~S}$ (with intermediate steps in which the unusual species $\mathrm{HS}_{2}^{+}, \mathrm{H}_{3} \mathrm{~S}_{2}^{+}, \mathrm{HS}_{2}$ and $\mathrm{H}_{2} \mathrm{~S}_{2}^{+}$are formed). Note that at lower temperatures $\mathrm{S}$ is oxygenated rather than hydrogenated, whereas at $300 \mathrm{~K}$ atomic oxygen goes into water and, therefore, $\mathrm{S}$ can be hydrogenated eventually.

As in the case of $\mathrm{H}_{2} \mathrm{~S}$, the initial (adopted) abundance of OCS is that derived from observations of this species in the solid state (see Sect. 2.1 and Table 2). Once in the gas phase, OCS is destroyed later than $\mathrm{H}_{2} \mathrm{~S}$. Under some conditions, e.g. $T=100 \mathrm{~K}$ and $n\left(\mathrm{H}_{2}\right)=10^{6}-10^{7} \mathrm{~cm}^{-3}$, this molecule maintains a sizable if reduced abundance. Actually, at $T=100 \mathrm{~K}$ and $n\left(\mathrm{H}_{2}\right)=10^{6}-10^{7} \mathrm{~cm}^{-3}$, there is even a temporary increase in the OCS abundance from $\sim 10^{-7}$ to $\sim 10^{-6}$ (see Fig. 3). The OCS molecule is mostly formed by the radiative association reaction $\mathrm{CO}+\mathrm{S} \rightarrow \mathrm{OCS}+\mathrm{PHOTON}$ and this reaction is aided by the high density.

Unlike the other species, the CS molecule does not start on grain mantles in our calculations, but is part of the preevaporative gas. For composition A, its initial abundance is rather low. At $100 \mathrm{~K}$, the initial CS is destroyed increasingly efficiently as density increases and its abundance never goes over $10^{-9}$. At $300 \mathrm{~K}, \mathrm{CS}$ is efficiently produced at high density after $10^{3} \mathrm{yr}$ and it can be as abundant as $10^{-8}$. For compositions $\mathrm{B}$ and $\mathrm{C}$, there is significantly more CS present initially, especially for composition $\mathrm{B}$, which contains 50 times more CS than in composition A. The initial CS is more slowly destroyed using compositions $\mathrm{B}$ and $\mathrm{C}$ than using composition $\mathrm{A}$ under the conditions depicted in Fig. 2 for models 2 and 4.

\subsection{Abundance ratios}

Abundance ratios between sulphur-bearing species are exceedingly important because the use of fractional abundances $\left(X(i)=N(i) / N\left(\mathrm{H}_{2}\right)\right)$ as chemical clocks introduces an additional parameter in the analysis - the $\mathrm{H}_{2}$ column density $\left(N\left(\mathrm{H}_{2}\right)\right)$ in the emitting region - which is rarely well constrained observationally. Moreover, the abundance ratios are less sensitive to the initial amount of sulphur species compared with absolute abundances. For example, an initial abundance of $\mathrm{S}$ or $\mathrm{S}_{2}$ two times less than those used in model 2 or 3 does

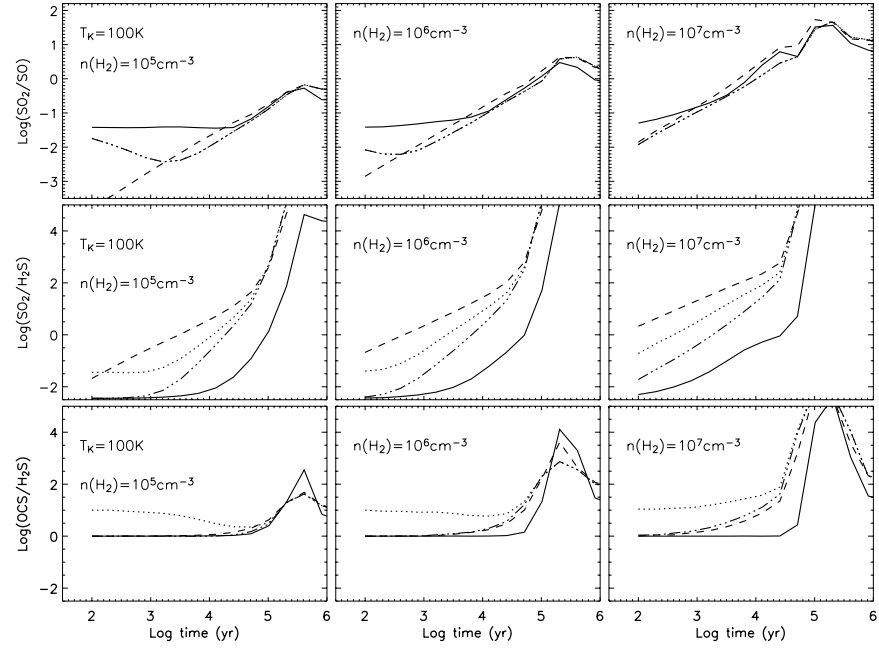

Fig. 5. Evolution of the abundance ratios $\mathrm{SO}_{2} / \mathrm{SO}$ (upper panels), $\mathrm{SO}_{2} / \mathrm{H}_{2} \mathrm{~S}$ (middle panels) and $\mathrm{OCS} / \mathrm{H}_{2} \mathrm{~S}$ (lower panels) as functions of time for composition A, a gas temperature of $100 \mathrm{~K}$, and densities of $10^{5} \mathrm{~cm}^{-3}$ (left panels), $10^{6} \mathrm{~cm}^{-3}$ (central panels) and $10^{7} \mathrm{~cm}^{-3}$ (right panels). The solid, dashed-dotted, dashed, and dotted lines represent results from models $1,2,3$, and 4, respectively. In the upper panels, the results of model 2 and 4 are the same and represented by dashed-dotted lines.

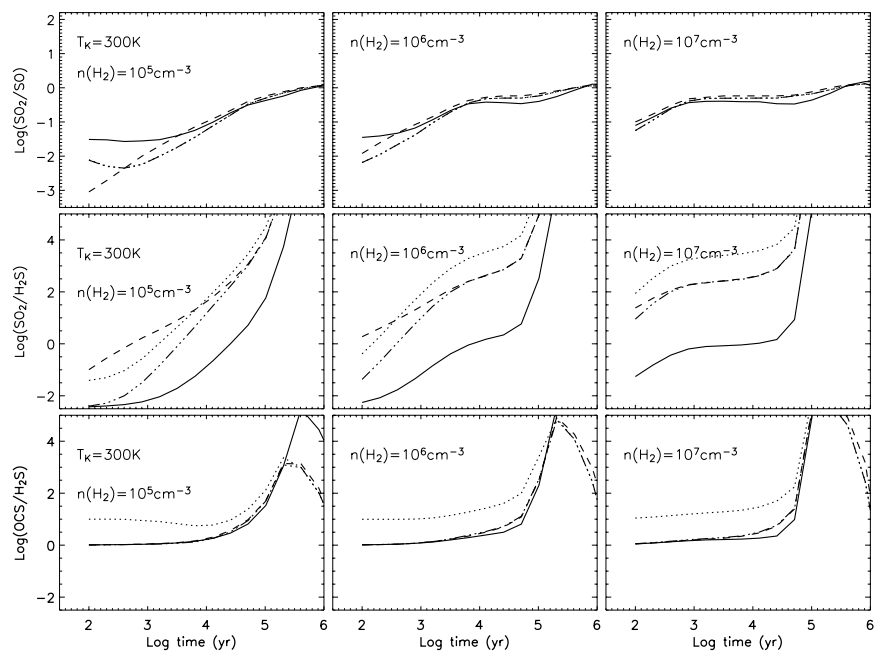

Fig. 6. Same as Fig. 5 but with a temperature of $300 \mathrm{~K}$.

not change significantly the abundance ratios. This is why observed abundance ratios are typically used to put contraints on chemical models, when the two species trace the same region.

Figures 5 and 6 show the evolution of the abundance ratios $\mathrm{SO}_{2} / \mathrm{SO}, \mathrm{SO}_{2} / \mathrm{H}_{2} \mathrm{~S}$ and $\mathrm{OCS} / \mathrm{H}_{2} \mathrm{~S}$, at $100 \mathrm{~K}$ and $300 \mathrm{~K}$ for three densities using composition $\mathrm{A}$ and all four models. The overall sense of these figures is that the computed ratios are more sensitive to the gas temperature, the density, and the (poorly known) form of sulphur in grain mantles than to the time (particularly for $t \leq 3 \times 10^{4} \mathrm{yr}$ ) or to the gas phase chemical history of the cloud. As a first step in quantifying the sensitivity of the studied abundance ratios to the different parameters, we report in Table 6 the maximum relative variation (MRV) for the three abundance ratios. These are obtained by changing the parameters time, temperature, density, model within the 
Table 6. Maximum sensitivity of the abundance ratios to assorted parameters.

\begin{tabular}{llrl}
\hline \hline Ratio & Changing parameter & MRV & Set of parameter \\
\hline $\mathrm{SO}_{2} / \mathrm{SO}$ & Time & 16 & $100 \mathrm{~K}, 10^{7} \mathrm{~cm}^{-3}$, Mod. 3 \\
& Temperature & 6 & $10^{4} \mathrm{yr}, 10^{5} \mathrm{~cm}^{-3}$, Mod. 4 \\
& Density & 125 & $10^{4} \mathrm{yr}, 100 \mathrm{~K}$, Mod. 3 \\
& Model & 20 & $10^{3} \mathrm{yr}, 100 \mathrm{~K}, 10^{5} \mathrm{~cm}^{-3}$ \\
\hline $\mathrm{SO}_{2} / \mathrm{H}_{2} \mathrm{~S}$ & Time & 330 & $300 \mathrm{~K}, 10^{5} \mathrm{~cm}^{-3}$, Mod. 2 \\
& Temperature & 630 & $10^{3} \mathrm{yr}, 10^{7} \mathrm{~cm}^{-3}$, Mod. 4 \\
& Density & 5000 & $10^{3} \mathrm{yr}, 300 \mathrm{~K}$, Mod. 4 \\
& Model & 3150 & $10^{4} \mathrm{yr}, 300 \mathrm{~K}, 10^{7} \mathrm{~cm}{ }^{-3}$ \\
\hline $\mathrm{OCS}^{\prime} \mathrm{H}_{2} \mathrm{~S}$ & Time & 6 & $100 \mathrm{~K}, 10^{7} \mathrm{~cm}^{-3}$, Mod. 2 \\
& Temperature & 3 & $10^{4} \mathrm{yr}, 10^{7} \mathrm{~cm}^{-3}$, Mod. 2 \\
& Density & 10 & $10^{4} \mathrm{yr}, 100 \mathrm{~K}, M_{0 .} 2$ \\
& Model & 30 & $10^{4} \mathrm{yr}, 100 \mathrm{~K}, 10^{7} \mathrm{~cm}^{-3}$ \\
\hline
\end{tabular}

following considered ranges: time, $10^{3}-10^{4} \mathrm{yr}$; temperature, $100-300 \mathrm{~K}$; density, $10^{5}-10^{7} \mathrm{~cm}^{-3}$; grain mantle composition, models $1-4$. The MRV is determined for each parameter by varying this parameter within the stated range while holding the others fixed at the set of values shown in Table 6. These sets lead to the strongest changes; hence the term "maximum relative variation". For example, the maximum variation of the $\mathrm{SO}_{2} / \mathrm{SO}$ ratio produced by an increase of the time from $10^{3}$ to $10^{4} \mathrm{yr}$ is 16 and it is obtained for a temperature of $100 \mathrm{~K}$, a density of $10^{7} \mathrm{~cm}^{-3}$ and model 3 .

The $\mathrm{SO}_{2} / \mathrm{H}_{2} \mathrm{~S}$ ratio shows the largest variations with time, but, unfortunately, also with differing physical conditions and mantle mixtures. Indeed the ratio is more sensitive to the latter parameters than to the time, for $t \leq 3 \times 10^{4} \mathrm{yr}$. The $\mathrm{OCS} / \mathrm{H}_{2} \mathrm{~S}$ ratio is less sensitive to the different mantle mixtures and physical conditions, except at late times $\left(\geq 10^{5} \mathrm{yr}\right)$. Unfortunately, however, this ratio is not sensitive to the time at $t \leq 10^{5} \mathrm{yr}$ either. The $\mathrm{SO}_{2} / \mathrm{SO}$ ratio shows significant variations with respect to the different mantle compositions, and different densities and temperatures at relatively early times $\left(\leq 10^{4} \mathrm{yr}\right)$. These variations mask completely the dependence on the time, which is, anyway, moderate at $100 \mathrm{~K}$ with the exception of the high density case, and small at $300 \mathrm{~K}$.

To gain an understanding of the sensitivities of these abundance ratios in addition to that obtained from the MRV analysis, we follow the variations of $\mathrm{SO}_{2} / \mathrm{SO}, \mathrm{SO}_{2} / \mathrm{H}_{2} \mathrm{~S}$ and $\mathrm{OCS} / \mathrm{H}_{2} \mathrm{~S}$ compared with reference ratios computed from model 2 at $10^{3} \mathrm{yr}$ for a temperature of $100 \mathrm{~K}$ and a density of $10^{5} \mathrm{~cm}^{-3}$ (left panels of Fig. 5). The reference $\mathrm{SO}_{2} / \mathrm{SO}$ ratio is $\sim 5 \times 10^{-3}$ and increases by only a factor of 2 by $10^{4} \mathrm{yr}$. However, a similar increase can also be due to an underestimate of the density by a factor of 10 (note that if $n_{\mathrm{H}_{2}}=10^{7} \mathrm{~cm}^{-3}$, the $\mathrm{SO}_{2} / \mathrm{SO}$ ratio increases by a factor of 20). Also, the reference $\mathrm{SO}_{2} / \mathrm{SO}$ ratio at $10^{3} \mathrm{yr}$ varies by a factor of $\sim 20$ depending on the adopted mantle mixture. The reference $\mathrm{SO}_{2} / \mathrm{H}_{2} \mathrm{~S}$ ratio is 0.01 and increases by one order of magnitude at $10^{4} \mathrm{yr}$. An increase in density (to $10^{7} \mathrm{~cm}^{-3}$ ) or in temperature (to $300 \mathrm{~K}$ ) gives respectively a ratio of 0.3 or 0.1 . The largest variation is seen if both the temperature and the density increase, so that the $\mathrm{SO}_{2} / \mathrm{H}_{2} \mathrm{~S}$ ratio jumps to 160 . A different mantle mixture leads to ratios between $3 \times 10^{-3}$ and 0.3 (at the reference time). The reference $\mathrm{OCS} / \mathrm{H}_{2} \mathrm{~S}$ ratio is 1 and shows little to no sensitivity to time until $10^{4} \mathrm{yr}$, but also evinces little change with temperature, density and mantle composition, with the exception of model 4 which gives a ratio enhanced by a factor of $\sim 10$ because the abundance of $\mathrm{H}_{2} \mathrm{~S}$ is 10 times less than in models 1, 2, and 3.

\section{Discussion}

\subsection{Comparison with previous models}

The most recent papers focussing on the detailed modelling of sulphur chemistry in hot cores are those of Charnley (1997) and Hatchell et al. (1998). The adopted chemistry is roughly the same in the two models, but they differ in the value of the activation energy barrier for the destruction of $\mathrm{H}_{2} \mathrm{~S}$ by atomic hydrogen $\left(\mathrm{H}_{2} \mathrm{~S}+\mathrm{H} \rightarrow \mathrm{HS}+\mathrm{H}_{2}\right)$. In particular, Hatchell et al. used a value of $350 \mathrm{~K}$ while Charnley used a value of $850 \mathrm{~K}$. Although there is some experimental support for a variety of choices, here we are using an energy barrier of $1350 \mathrm{~K}$, based on the recent experiment by Peng et al. (1999) in the 300-600 K range. The difference in the activation energy barrier for the $\mathrm{H}_{2} \mathrm{~S}+\mathrm{H}$ reaction causes significant variations in the models. While we obtain results similar to the Charnley model for $100 \mathrm{~K}, \mathrm{H}_{2} \mathrm{~S}$ destruction occurs at later times in our model for $T=300 \mathrm{~K}$. Moreover, the high value of the energy barrier has significant consequences on the $\mathrm{SO}$ and $\mathrm{SO}_{2}$ abundances of our model with respect to the above two models. For example at $10^{4} \mathrm{yr}$, our model predicts $\mathrm{SO}$ and $\mathrm{SO}_{2}$ abundances 6 and 30 times lower than Charnley's model, using the same parameters and initial conditions. Overall, and in addition to this, our results are different from these two models primarily because we are assuming different initial gas phase and/or mantle compositions. As already noted (in Sect. 3.1), the large atomic oxygen abundance is, for example, an important difference in the pre-evaporated gas phase composition. Another difference is that both Charnley and Hatchell et al. assume that the bulk of sulphur in the ice mantle is in the $\mathrm{H}_{2} \mathrm{~S}$ form. Our model 1 adopts a similar mantle mixture, with solid-phase OCS as abundant as $\mathrm{H}_{2} \mathrm{~S}$, whereas models 2, 3 and 4 assume that the bulk of the sulphur lies in the $\mathrm{S}$ or $\mathrm{S}_{2}$ forms. These two classes of models give very different results, as widely discussed in Sect. 3.

Actually, a novelty of this work is the consideration that the sulphur can be in the atomic or molecular form when evaporated from the grain mantles. However, we should emphasize that atomic $\mathrm{S}$ is very quickly locked into $\mathrm{SO}$ and $\mathrm{SO}_{2}$ molecules, so that we do not expect large atomic $\mathrm{S}$ quantities in the gas phase for a long time. For example, for a gas at $300 \mathrm{~K}$ and $10^{7} \mathrm{~cm}^{-3}$, the $\mathrm{S}$ abundance decreases from $3 \times 10^{-5}$ to $1.5 \times 10^{-9}$ in $10^{3} \mathrm{yr}$ by reacting with $\mathrm{O}_{2}$ to form SO. This explains why van der Tak et al. (2003) did 
not detect atomic sulphur ${ }^{1}$ in the hot core region of the massive protostars that they studied, where the gas temperature and density are similar to those quoted above. In a slightly colder gas $(\sim 100 \mathrm{~K})$, atomic $\mathrm{S}$ would survive longer, but it would be very difficult to detect. In fact the intensity of the SI fine structure line at $25.249 \mu \mathrm{m}$ is $1 \times 10^{-12} \mathrm{erg} \mathrm{s}^{-1} \mathrm{~cm}^{-2}$, for a gas at $100 \mathrm{~K}$ and $10^{7} \mathrm{~cm}^{-3}$, a source size of $2^{\prime \prime}$, an $\mathrm{H}_{2}$ column density of $10^{23} \mathrm{~cm}^{-2}$, and all the sulphur in atomic form (as our models 2 and 4 adopt). The signal would be attenuated by the foreground dust of the cold envelope, whose $\mathrm{H}_{2}$ column density is also around $10^{23} \mathrm{~cm}^{-2}$, by about a factor of ten (using the extinction curves in Draine 2003) putting the signal at the limit of the ISO-SWS detection (a typical rms is few times $10^{-13} \mathrm{erg} \mathrm{s}^{-1} \mathrm{~cm}^{-2}$ ). Future investigations in the ISO database will be done in order to check the possible presence of atomique sulphur in hot cores.

Hatchell et al. (1998) found the cosmic ray rate to be an important parameter changing the timescales of the destruction of $\mathrm{H}_{2} \mathrm{~S}$ and the formation of $\mathrm{SO}$ and $\mathrm{SO}_{2}$. The standard value usually assumed is $1.3 \times 10^{-17} \mathrm{~s}^{-1}$ but there are some indications that it can vary depending on the region (see van der Tak $\&$ van Dishoeck 2000). To check the dependence on ionization rate whether or not it can pertain to objects as dense as hot cores, we have run the models for three different cosmic ray ionization rates: $1.3 \times 10^{-17}, 1.3 \times 10^{-16}$ and $1.3 \times 10^{-15} \mathrm{~s}^{-1}$. The results for the $S$-bearing abundance ratios do not strongly depend on this parameter at a density of $10^{5} \mathrm{~cm}^{-3}$. At higher densities, however, an increase in the cosmic ray ionization rate speeds up the photodestruction of OCS, $\mathrm{H}_{2} \mathrm{~S}$ and $\mathrm{SO}_{2}$ via cosmic ray-induced photons. For a cosmic ray ionization rate of $1.3 \times 10^{-15} \mathrm{~s}^{-1}$, a temperature of $100 \mathrm{~K}$ and a density of $10^{7} \mathrm{~cm}^{-3}$, the abundances of $\mathrm{H}_{2} \mathrm{~S}$ and OCS start to decrease before $10^{3} \mathrm{yr}$ and the maximum abundance of $\mathrm{SO}_{2}$ is $4.5 \times 10^{-8}$ instead of $2 \times 10^{-7}$ with model 1 and composition A. Hence, as Hatchell et al. (1998), we found that the adopted value of the cosmic ray rate may be an important parameter at high density whereas it has weak consequences on the results at lower densities.

Recently, Nomura \& Millar (2004) reported a study of the chemical composition across the envelope of the massive protostar G24.3+0.15. In this study, they derived the density and temperature profile and computed the chemical composition of the gas as a function of the radius and time. Evidently, the Nomura \& Millar (2004) model is more complete than ours in dealing with the physical structure of the protostar, for this is the focus of their model. On the other hand, given its complexity, the model does not explore the robustness of the achieved results as a function of the necessary assumptions of the model itself, which is, on the contrary, the focus of our study. In the same way, Doty et al. (2002) studied the chemical composition across the envelope of the massive protostar AFGL 2591.

\footnotetext{
${ }^{1}$ van der Tak et al. (2003) argued that the non detection of the $25 \mu \mathrm{m}$ line corresponds to an upper limit to the atomic sulphur of $\leq 5 \times 10^{-8}$, computed by considering line absorption. Indeed, this is an upper limit on the $\mathrm{S}$ abundance in the absorbing gas, i.e. the foreground cold gas, rather than the hot gas. The upper limit on the emitting hot core gas is much higher, as explained in the text.
}

Finally, a further degree of complexity has been added to the problem by Rodgers \& Charnley (2003), who considered the evolution of a protostar, including the evolution of the thermal and physical structure of the envelope plus the chemical evolution. As in the previous case, the advantage of having a better description of the protostar comes along with the disadvantage of a lack of exploration of the robustness of the results as a function of the chemical network utilized. In these three models, the authors assumed that sulphur was only evaporated from the grains mantles in the OCS and $\mathrm{H}_{2} \mathrm{~S}$ forms for Nomura \& Millar (2004) and only in the $\mathrm{H}_{2} \mathrm{~S}$ form for Doty et al. (2002) and Rodgers \& Charnley (2003). We have discussed above the problem with the assumption that sulphur is totally frozen onto OCS and $\mathrm{H}_{2} \mathrm{~S}$, and showed that the resulting S-bearing abundances depend dramatically on this assumption. The conclusion is the same if considering a model where sulphur is only in $\mathrm{H}_{2} \mathrm{~S}$ (as discussed at the end of Sect. 4.2). It comes as no surprise, therefore, that our results are different from those of these more detailed approaches.

\subsection{Comparison with observations}

In the following, we consider the case of two well studied hot cores: the massive Orion KL and the low mass IRAS 16293-2422 hot cores. Orion KL is a complex region where several energetic phenomena are present. High resolution, interferometric observations have shown that different molecules originate in different components, especially for the OCS, SO and $\mathrm{SO}_{2}$ molecules (e.g., Wright et al. 1996). It is evidently a very crude approximation to attribute all the S-molecule emission to the hot core, but lacking a better understanding of the region we will try to compare the observed abundances with our model predictions. First, in order to minimise the number of parameters, we will compare available observations with computed abundance ratios. The $\mathrm{SO}, \mathrm{SO}_{2}$, $\mathrm{H}_{2} \mathrm{~S}$ and OCS column densities have been derived by Schilke et al. (2001) and Sutton et al. (1995) to be $2.3 \times 10^{17}, 6 \times 10^{16}$, $1.2 \times 10^{16} \mathrm{~cm}^{-2}$ and $9 \times 10^{15} \mathrm{~cm}^{-2}$, respectively. All these column densities are beam-averaged, with a beam of $\sim 10^{\prime \prime}$. For simplicity, we will assume that the emission originates in the hot core region with $T=200 \mathrm{~K}$ and $n\left(\mathrm{H}_{2}\right)=10^{7} \mathrm{~cm}^{-3}$ (Wright et al. 1992). The comparison of the abundance ratios derived from the above column densities with our model predictions shows that none of the four models of Sect. 2.1 reproduces the observed data. However, the ratios can be reproduced by a model similar to model 2 , where the initial abundance of atomic sulphur injected into the gas phase is $3 \times 10^{-6}$, i.e. ten times lower than the abundance used in model 2. We will call this model model $2^{\prime}$. In that case, we obtain a good agreement between the model and the observations and derive an age of $4 \times 10^{3} \mathrm{yr}$. Assuming the emission region extends about $10^{\prime \prime}$ and an $\mathrm{H}_{2}$ column density of $8 \times 10^{23} \mathrm{~cm}^{-2}$ (Sutton et al. 1995), the observed abundances of $\mathrm{SO}, \mathrm{SO}_{2}, \mathrm{H}_{2} \mathrm{~S}$ and OCS are reproduced to within a factor of 10 . On the contrary, the CS abundance is underestimated by three orders of magnitude by our model, probably because CS emission does not originate in the hot core. Note that, given the complexity of the region, a 

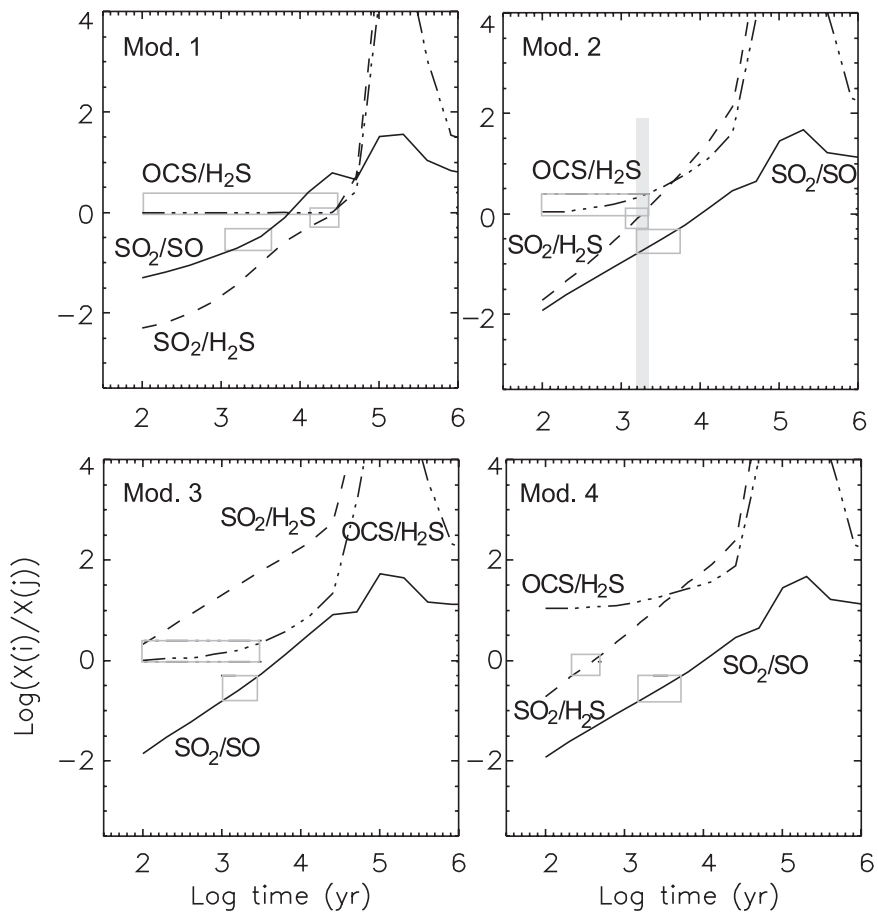

Fig. 7. Comparison between the observed ratios $\mathrm{SO}_{2} / \mathrm{SO}, \mathrm{SO}_{2} / \mathrm{H}_{2} \mathrm{~S}$ and $\mathrm{OCS} / \mathrm{H}_{2} \mathrm{~S}$ towards IRAS $16293-2422$ and the theoretical predictions of four models (Mod. 1, 2, 3 and 4; all with composition A) for a gas temperature of $100 \mathrm{~K}$ and a density of $10^{7} \mathrm{~cm}^{-3}$. The grey empty boxes, if shown, represent those instances in which particular calculated ratios are in agreement for a range of times with the observed ones taking into account the uncertainties in the observations. The grey filled box for model 2 shows the time interval where all calculated ratios are in agreement with the observed ones.

better analysis would require an understanding of the $\mathrm{H}_{2}$ column density associated with the S-bearing molecules.

In the case of the low-mass protostar IRAS 16293-2422, multifrequency observations of $\mathrm{H}_{2} \mathrm{~S}, \mathrm{OCS}, \mathrm{SO}$ and $\mathrm{SO}_{2}$ have been reported and analyzed by sophisticated models, which take into account the density and temperature structure of the source, as well as the abundance profile of each studied molecule (Schöier et al. 2002; Wakelam et al. 2004). Both Schöier et al. (2002) and Wakelam et al. (2004) found the following abundance ratios in the inner warm region where the dust mantles evaporate (Ceccarelli et al. 2000a): $\mathrm{SO}_{2} / \mathrm{SO}=$ $0.3, \mathrm{SO}_{2} / \mathrm{H}_{2} \mathrm{~S}=1$ and $\mathrm{OCS} / \mathrm{H}_{2} \mathrm{~S}=1.9$.

The modelling of the density and temperature profiles of IRAS 16293-2422, by Ceccarelli et al. (2000a), suggests a density of $10^{7} \mathrm{~cm}^{-3}$ and a temperature of $100 \mathrm{~K}$ in the hot core region. Figure 7 shows the comparison between the observed and predicted ratios (assuming composition A) for the four models: only model 2 reproduces the observations, suggesting an age of $\sim 2 \times 10^{3} \mathrm{yr}$ for the protostar. To check the robustness of this result, we also tried a variety of intermediate mantle mixtures, between model 2 and model 3, with the following characteristics: (1) one-half of the initial mantle sulphur in atomic form and one-half in the form of $S_{2}$; (2) one-quarter in $S$ and three-quarters in $S_{2}$; (3) three-quarters in $\mathrm{S}$ and one-quarter in $\mathrm{S}_{2}$. In all three intermediate cases, the
Table 7. Observed and modelled abundances of SO, $\mathrm{SO}_{2}, \mathrm{H}_{2} \mathrm{~S}$, OCS and CS towards the IRAS 16293-2422 hot core.

\begin{tabular}{l|ccc}
\hline \hline Species & observed & model 2 & model 2' \\
\hline $\mathrm{SO}$ & $1.7 \times 10^{-6}$ & $5 \times 10^{-7}$ & $4 \times 10^{-7}$ \\
$\mathrm{SO}_{2}$ & $5.4 \times 10^{-7}$ & $10^{-7}$ & $10^{-7}$ \\
$\mathrm{H}_{2} \mathrm{~S}$ & $5.3 \times 10^{-7}$ & $10^{-7}$ & $10^{-7}$ \\
$\mathrm{OCS}$ & $1 \times 10^{-6}$ & $2 \times 10^{-7}$ & $10^{-7}$ \\
$\mathrm{CS}$ & - & $1 \times 10^{-11}$ & $2 \times 10^{-12}$ \\
\hline
\end{tabular}

resulting curves are very similar to those found for model 3. The presence of molecular sulphur clearly determines the form of the curves and is inconsistent with these observations. The observed ratios are, however, well reproduced by model $2^{\prime}$ (used for the comparison with Orion) giving an age, $\sim 3 \times 10^{3} \mathrm{yr}$, very similar to the age derived by model 2 . Finally, both model 2 and model $2^{\prime}$ predict fractional abundances at the optimum times in good agreement (within a factor of 5-10) with those observed, as reported in Table 7. Note that the CS abundance towards IRAS 16293-2422 has not been derived (Schöier et al. 2002; Wakelam et al. 2004) and that the abundances of the main S-bearing species predicted by model 2 and $2^{\prime}$ are very similar until $10^{4} \mathrm{yr}$. This comparison suggests that the majority of the sulphur is released into the gas phase in its atomic form or quickly $\left(t \leq 10^{3} \mathrm{yr}\right.$ ) converted to it, and that the abundance of the $\mathrm{H}_{2} \mathrm{~S}$ molecule injected in the gas phase from the grains mantles cannot be much less than $10^{-7}$.

The age determined for IRAS 16293-2422 is relatively short compared with the previous estimates $\left(\sim 10^{4} \mathrm{yr}\right)$ (Ceccarelli et al. 2000b; Maret et al. 2002; Wakelam et al. 2004). However, our newly determined age represents only the time from the evaporation of the mantles; the dynamical time needed to reach the required luminosity to form the observed hot core is an additional $\sim 3 \times 10^{4} \mathrm{yr}$.

The discussion of the best chemical age for IRAS $16293-2422$ is based on models with the standard value of the cosmic ray ionization rate $\left(1.3 \times 10^{-17} \mathrm{~s}^{-1}\right)$. If we use a rate 10 times higher as suggested by Doty et al. (2004), the observations towards IRAS 16293-2422 are no longer in agreement with model 2 , but with model 1, although the derived age is very similar. Indeed, the enhanced cosmic ray ionization rate speeds up the destruction of $\mathrm{H}_{2} \mathrm{~S}$, increasing the ratio $\mathrm{SO}_{2} / \mathrm{H}_{2} \mathrm{~S}$ more rapidly without affecting significantly the other ones. Consequently, the $\mathrm{SO}_{2} / \mathrm{H}_{2} \mathrm{~S}$ curves in Fig. 7 are shifted to the right of the figures, worsening the agreement with model 2 but improving it with model 1 . In that case, the derived age is $5 \times 10^{3} \mathrm{yr}$ and the predicted absolute abundances are between 15 and 20 less than the observed ones, however. Thus, a high cosmic ray ionization rate is no longer compatible with our hypothesis that mantle evaporation leads quickly to high gas-phase abundances of atomic sulphur. The high cosmic ray ionization rate has also a consequence on the $\mathrm{O}_{2}$ abundance pedicted to be $\sim 10^{-6}$ at $10^{3}$ yr with model 1 whereas it is predicted to be two orders of magnitude lower with the standard value of the cosmic ray ionization rate and model 2. However, at present one cannot choose between the 
two conditions (large abundances of $\mathrm{S}$ in the gas phase or large cosmic-ray ionization rate). High sensitivity observations of atomic sulphur (see Sect. 4.1) are needed to put stringent constraints on chemical models.

Another way to confirm our hypothesis of a large initial abundance of atomic sulfur would be a careful study involving several other protostars at different stages of evolution. The strongest prediction of our models 2 to 4 is the large $\left(\gtrsim 10^{-5}\right)$ amount of $\mathrm{SO}_{2}$ at late times, compared with models that start with little sulphur evaporated from the grains. There is some evidence for $\mathrm{SO}_{2}$ abundances in high-mass hot cores as large as $10^{-6}$ (van der Tak et al. 2003), suggesting that an initial amount of sulphur at least higher than $10^{-6}$ is needed. But our prediction of large $\mathrm{SO}_{2}$ abundances in more evolved hot cores with ages larger than $\sim 10^{5} \mathrm{yr}$, does not pertain to the Orion and IRAS 16293-2422 hot cores (as found in the present work).

Quantitative comparisons with observations of other hot cores reported in the literature, such as the observations by Hatchell et al. (1998) and Buckle \& Fuller (2003), are difficult to carry out since the abundances determined by these authors are averages along the line of sight and beam-averaged. Hence, their analyses do not take into account the physical structure of the source. Finally, van der Tak et al. (2003) report the study of the S-bearing molecular abundance in half a dozen massive protostars. In this case, an attempt to disentangle the outer envelope and inner core has been done, but the analysis is not accurate enough to derive abundance ratios to compare with detailed model predictions; rather, the authors just give orderof-magnitude jumps of abundance in the inner hot core regions. van der Tak et al. (2003) compared the measured abundances with the model predictions by Doty et al. (2002), and argued that OCS is the main sulphur bearing molecules on the mantles, because its predicted abundance is otherwise too low. We ran a model where sulphur is in solid OCS, to test this suggestion, and we found that it leads to results very similar to those of model 1 (where sulphur is evaporated from the grain mantles in the $\mathrm{H}_{2} \mathrm{~S}$ and OCS forms), because OCS has almost the same chemical behavior as $\mathrm{H}_{2} \mathrm{~S}$. Although OCS is destroyed at later times, the differences in the $\mathrm{SO}$ and $\mathrm{SO}_{2}$ formation are not significant and the same discussion about model 1 is valid.

\section{Conclusions}

We have studied in detail the influence of the mantle form of sulphur on the post-evaporative gas-phase abundances of S-bearing molecules in hot star-forming regions, with the goal of understanding whether those molecules can be used to estimate ages. We considered four different reasonable mantle mixtures, from which gas-phase $\mathrm{H}_{2} \mathrm{~S}, \mathrm{OCS}, \mathrm{S}$ and $\mathrm{S}_{2}$ emerge after a process of evaporation and, for the last two species, possible rapid reaction, with different relative abundances, joining other species in the gas-phase prior to evaporation. We then followed the post-evaporative chemical evolution, with an emphasis on the abundance ratios of the main sulphur-bearing species for realistic physical conditions present in hot cores. Our results show that none of the ratios involving the four most abundant S-bearing molecules, namely $\mathrm{H}_{2} \mathrm{~S}$, OCS, $\mathrm{SO}$ and $\mathrm{SO}_{2}$, can be easily used by itself for estimating the age, because the ratios depend at least as strongly on the physical conditions and on the adopted grain mantle composition as on the time. Also, the abundance of atomic oxygen in the gas phase, if not correctly accounted for, can seriously affect the chemistry. The situation, however, is not totally hopeless, because a careful comparison between observations and model predictions can give some useful hints on time estimates, and on the mantle composition. Such a careful analysis has to be done on each single source, however, for both the physical conditions and mantle composition can vary from source to source, so that the abundance ratios are not directly comparable. In practice, a careful derivation of the molecular abundances (which takes into account the source structure) coupled with a careful modeling of the chemistry at the right gas temperature and density is necessary.

We applied our model to two well studied hot cores: Orion KL and IRAS 16293. For the S-bearing abundances towards Orion KL, we assumed that their emission arises from the hot core region (which is strongly debatable) and is not beam-diluted. We were not able to reproduce all of the observed abundances ratios with any of our models. The agreement with model 2 is satisfactory if we decrease the initial amout of atomic sulphur by a factor of 10 . In that case, we derive a best age of $4 \times 10^{3} \mathrm{yr}$. However, the predicted abundance of CS is three orders of magnitude lower than the observed one. Contrary to the case of Orion KL, the sulphur-bearing abundances though the low mass hot core of IRAS 16293-2422 have been carefully determined through a sophisticated model (Schöier et al. 2002), which takes into account the density and temperature structure of the source, as well as the abundance profile of each studied molecule. Using the standard value of cosmic ray rate, we found that model 2 , in which a large amount of atomic sulphur is initially present in the post-evaporative gas, best reproduces the observed abundance ratios. In that case, we derived an age of $\sim 2 \times 10^{3} \mathrm{yr}$ from the evaporation era to the current stage of this particular low mass hot core. If we decrease the initial amount of atomic sulphur in model 2 as for Orion KL, the agreement is still good and gives a similar age. This analysis favors the hypothesis that sulphur is mainly evaporated from the grains in the atomic form or in a form quickly converted into it. On the contrary, if a higher rate is used as suggested by the recent modelling of Doty et al. (2004), best agreement occurs with model 1, where no atomic sulphur can be found in the grain mantle and only $\mathrm{H}_{2} \mathrm{~S}$ and OCS are initially present. The strongest prediction of our atomic sulfurrich model is the presence of large abundances of $\mathrm{SO}_{2}$, derived from this form of sulfur, at late stages of hot cores. A futher systematic study of S-bearing-species towards older hot cores where the physical structure is well known would provide information to test this model. Moreover, the fact that not all of the sulfur need be initially in atomic form, given the reasonable agreement obtained using model $2^{\prime}$, suggests that a significant portion of the granular elemental sulphur may be tied up in materials such as iron sulphide (Keller et al. 2002).

Acknowledgements. V.W. wishes to thank Franck Selsis for helpful discussions on chemical modelling and uncertainties. V.W., C.C. and A.C. acknowledge support from PCMI. P.C. acknowledges support from the MIUR grant "Dust and molecules in astrophysical environments", and the ASI grant (contract I/R/044/02). 
E.H. acknowledges the support of the National Science Foundation (US) for his research program in astrochemistry. The authors are grateful to Brunella Nisini and Malcolm Walmsley for useful discussions.

\section{References}

Aikawa, Y., Herbst, E., \& Dzegilenko, F. N. 1999, ApJ, 527, 262 Baluteau, J.-P., Cox, P., Cernicharo, J., et al. 1997, A\&A, 322, L33 Bergin, E. A., Kaufman, M. J., Melnick, G. J., Snell, R. L., \& Howe, J. E. 2003, ApJ, 582, 830

Boogert, A. C. A., Helmich, F. P., van Dishoeck, E. F., et al. 1998, A\&A, 336, 352

Boogert, A. C. A., Tielens, A. G. G. M., Ceccarelli, C., et al. 2000, A\&A, 360, 683

Brown, P. D., Charnley, S. B., \& Millar, T. J. 1988, MNRAS, 231, 409

Buckle, J. V., \& Fuller, G. A. 2003, A\&A, 399, 567

Cardelli, J. A., Meyer, D. M., Jura, M., \& Savage, B. D. 1996, ApJ, 467, 334

Caselli, P., Hasegawa, T. I., \& Herbst, E. 1993, ApJ, 408, 548

Caselli, P., Hasegawa, T. I., \& Herbst, E. 1994, ApJ, 421, 206

Caux, E., Ceccarelli, C., Castets, A., et al. 1999, A\&A, 347, L1

Ceccarelli, C., Hollenbach, D. J., \& Tielens, A. G. G. M. 1996, ApJ, 471,400

Ceccarelli, C., Castets, A., Caux, E., et al. 2000a, A\&A, 355, 1129

Ceccarelli, C., Loinard, L., Castets, A., Tielens, A. G. G. M., \& Caux, E. 2000b, A\&A, 357, L9

Charnley, S. B. 1997, ApJ, 481, 396

Charnley, S. B., Tielens, A. G. G. M., \& Millar, T. J. 1992, ApJ, 399, L71

Charnley, S. B., Rodgers, S. D., \& Ehrenfreund, P. 2001, A\&A, 378, 1024

Chiar, J. E., Adamson, A. J., \& Whittet, D. C. B. 1996, ApJ, 472, 665

Dickens, J. E., Irvine, W. M., Snell, R. L., et al. 2000, ApJ, 542, 870

Doty, S. D., van Dishoeck, E. F., van der Tak, F. F. S., \& Boonman, A. M. S. 2002, A\&A, 389, 446

Doty, S. D., Schöier, F. L., \& van Dishoeck, E. F. 2004, A\&A, 418, 1021

Draine, B. T. 2003, ARA\&A, 41, 241

Gerakines, P. A., Whittet, D. C. B., Ehrenfreund, P., et al. 1999, ApJ, 522, 357

Gibb, E. L., Whittet, D. C. B., Schutte, W. A., et al. 2000, ApJ, 536, 347

Hartquist, T. W., Dalgarno, A., \& Oppenheimer, M. 1980, ApJ, 236, 182

Hasegawa, T. I., \& Herbst, E. 1993, MNRAS, 261, 83

Hasegawa, T. I., Herbst, E., \& Leung, C. M. 1992, ApJS, 82, 167

Hatchell, J., Thompson, M. A., Millar, T. J., \& MacDonald, G. H. 1998, A\&A, 338, 713
Hollenbach, D., \& McKee, C. F. 1979, ApJS, 41, 555

Keane, J. V., Tielens, A. G. G. M., Boogert, A. C. A., Schutte, W. A., \& Whittet, D. C. B. 2001, A\&A, 376, 254

Keller, L. P., Hony, S., Bradley, J. P., et al. 2002, Nature, 417, 148

Lee, H.-H., Bettens, R. P. A., \& Herbst, E. 1996, A\&AS, 119, 111

Lis, D. C., Keene, J., Phillips, T. G., et al. 2001, ApJ, 561, 823

Maret, S., Ceccarelli, C., Caux, E., Tielens, A. G. G. M., \& Castets, A. 2002, A\&A, 395, 573

Meyer, D. M., Jura, M., \& Cardelli, J. A. 1998, ApJ, 493, 222

Millar, T. J., Farquhar, P. R. A., \& Willacy, K. 1997a, A\&AS, 121, 139

Millar, T. J., MacDonald, G. H., \& Gibb, A. G. 1997b, A\&A, 325, 1163

Nomura, H., \& Millar, T. J. 2004, A\&A, 414, 409

Pagani, L., Olofsson, A. O. H., Bergman, P., et al. 2003, A\&A, 402, L77

Palumbo, M. E., Geballe, T. R., \& Tielens, A. G. G. M. 1997, ApJ, 479, 839

Peng, J., Hu, X., \& Marshall, P. 1999, J. Phys. Chem., 103, 5307

Pineau Des Forêts, G., Roueff, E., Schilke, P., \& Flower, D. R. 1993 , MNRAS, 262, 915

Rodgers, S. D., \& Charnley, S. B. 2003, ApJ, 585, 355

Ruffle, D. P., Hartquist, T. W., Caselli, P., \& Williams, D. A. 1999, MNRAS, 306, 691

Ruffle, D. P., Rae, J. G. L., Pilling, M. J., Hartquist, T. W., \& Herbst, E. 2002, A\&A, 381, L13

Scappini, F., Cecchi-Pestellini, C., Smith, H., Klemperer, W., \& Dalgarno, A. 2003, MNRAS, 341, 657

Schilke, P., Benford, D. J., Hunter, T. R., Lis, D. C., \& Phillips, T. G. 2001, ApJS, 132, 281

Schöier, F. L., Jorgensen, J. K., van Dishoeck, E. F., \& Blake, G. A. 2002, A\&A, 390, 1001

Schutte, W. A., Tielens, A. G. G. M., Whittet, D. C. B., et al. 1996, A\&A, 315, L333

Sofia, U. J., Cardelli, J. A., \& Savage, B. D. 1994, ApJ, 430, 650

Sutton, E. C., Peng, R., Danchi, W. C., et al. 1995, ApJS, 97, 455

Tieftrunk, A., Pineau Des Forets, G., Schilke, P., \& Walmsley, C. M. 1994, A\&A, 289, 579

van der Tak, F. F. S., Boonman, A. M. S., Braakman, R., \& van Dishoeck, E. F. 2003, A\&A, 412, 133

van der Tak, F. F. S., \& van Dishoeck, E. F. 2000, A\&A, 358, L79

van Dishoeck, E. F., \& Blake, G. A. 1998, ARA\&A, 36, 317

Vastel, C., Polehampton, E. T., Baluteau, J.-P., et al. 2002, ApJ, 581, 315

Viti, S., \& Williams, D. A. 1999, MNRAS, 305, 755

Wakelam, V., Castets, A., Ceccarelli, C., et al. 2004, A\&A, 413, 609

Wright, M., Sandell, G., Wilner, D. J., \& Plambeck, R. L. 1992, ApJ, 393, 225

Wright, M. C. H., Plambeck, R. L., \& Wilner, D. J. 1996, ApJ, 469, 216 
V. Wakelam et al.: S-molecules as chemical clocks, Online Material p 1

\section{Online Material}


V. Wakelam et al.: S-molecules as chemical clocks, Online Material p 2

Table 3. List of the reactions important for the chemistry of the $\mathrm{SO}, \mathrm{SO}_{2}, \mathrm{OCS}, \mathrm{H}_{2} \mathrm{~S}$ and CS molecules for a temperature of $100 \mathrm{~K}$ and a density of $10^{7} \mathrm{~cm}^{-3}$ with initial composition A.

\begin{tabular}{|c|c|c|c|c|c|c|c|c|}
\hline Number & Reaction $^{1}$ & $\bar{\alpha}$ & $\beta$ & $\gamma$ & Mod. 1 & Mod. 2 & Mod. 3 & Mod. 4 \\
\hline 89 & $\mathrm{H}_{2}+\mathrm{CRP} \rightarrow \mathrm{H}^{+}+\mathrm{H}+\mathrm{e}^{-}$ & $2.860 \mathrm{e}-19$ & 0.00 & 0.00 & & & $\bullet$ & \\
\hline 90 & $\mathrm{H}_{2}+\mathrm{CRP} \rightarrow \mathrm{H}_{2}^{+}+\mathrm{e}^{-}$ & & & & $\bullet$ & $\bullet$ & $\bullet$ & $\bullet$ \\
\hline 91 & $\mathrm{He}+\mathrm{CRP} \rightarrow \mathrm{He}^{+}+\mathrm{e}^{-}$ & & & & $\bullet$ & $\bullet$ & $\bullet$ & $\bullet$ \\
\hline 100 & $\mathrm{CH}_{4}+\mathrm{CRPHOT} \rightarrow \mathrm{CH}_{2}+\mathrm{H}_{2}$ & $6.08 \mathrm{e}-14$ & 0.00 & 0.00 & & $\bullet$ & $\bullet$ & $\bullet$ \\
\hline 106 & $\mathrm{H}_{2} \mathrm{O}+\mathrm{CRPHOT} \rightarrow \mathrm{OH}+\mathrm{H}$ & $2.52 \mathrm{e}-14$ & 0.00 & 0.00 & $\bullet$ & $\bullet$ & $\bullet$ & $\bullet$ \\
\hline 117 & $\mathrm{~S}+\mathrm{CRPHOT} \rightarrow \mathrm{S}^{+}+\mathrm{e}^{-}$ & $2.49 \mathrm{e}-14$ & 0.00 & 0.00 & & $\bullet$ & & $\bullet$ \\
\hline 119 & $\mathrm{H}_{2} \mathrm{~S}+\mathrm{CRPHOT} \rightarrow \mathrm{S}+\mathrm{H}_{2}$ & $1.34 \mathrm{e}-13$ & 0.00 & 0.00 & $\bullet$ & $\bullet$ & $\bullet$ & \\
\hline 120 & $\mathrm{H}_{2} \mathrm{~S}+\mathrm{CRPHOT} \rightarrow \mathrm{H}_{2} \mathrm{~S}^{+}+\mathrm{e}^{-}$ & $4.41 \mathrm{e}-14$ & 0.00 & 0.00 & $\bullet$ & & $\bullet$ & \\
\hline 125 & $\mathrm{SO}+\mathrm{CRPHOT} \rightarrow \mathrm{SO}^{+}+\mathrm{e}^{-}$ & $1.30 \mathrm{e}-14$ & 0.00 & 0.00 & & & $\bullet$ & \\
\hline 127 & $\mathrm{OCS}+\mathrm{CRPHOT} \rightarrow \mathrm{S}+\mathrm{CO}$ & $1.39 \mathrm{e}-13$ & 0.00 & 0.00 & $\bullet$ & & & \\
\hline 128 & $\mathrm{OCS}+\mathrm{CRPHOT} \rightarrow \mathrm{OCS}^{+}+\mathrm{e}^{-}$ & $3.76 \mathrm{e}-14$ & 0.00 & 0.00 & $\bullet$ & $\bullet$ & $\bullet$ & $\bullet$ \\
\hline 167 & $\mathrm{C}+\mathrm{SO} \rightarrow \mathrm{CS}+\mathrm{O}$ & $3.50 \mathrm{e}-11$ & 0.00 & 0.00 & & $\bullet$ & $\bullet$ & $\bullet$ \\
\hline 168 & $\mathrm{C}+\mathrm{SO}_{2} \rightarrow \mathrm{CO}+\mathrm{SO}$ & & & & & & $\bullet$ & \\
\hline 176 & $\mathrm{CH}_{2}+\mathrm{S} \rightarrow \mathrm{CS}+\mathrm{H}_{2}$ & & & & & $\bullet$ & & $\bullet$ \\
\hline 191 & $\mathrm{O}+\mathrm{CS} \rightarrow \mathrm{CO}+\mathrm{S}$ & $1.94 \mathrm{e}-11$ & 0.00 & 231.00 & $\bullet$ & $\bullet$ & $\bullet$ & $\bullet$ \\
\hline 207 & $\mathrm{O}_{2}+\mathrm{S} \rightarrow \mathrm{SO}+\mathrm{O}$ & $2.30 \mathrm{e}-12$ & 0.00 & 0.00 & $\bullet$ & & & \\
\hline 269 & $\mathrm{H}_{3}^{+}+\mathrm{O} \rightarrow \mathrm{OH}^{+}+\mathrm{H}_{2}$ & & & & $\bullet$ & $\bullet$ & $\bullet$ & $\bullet$ \\
\hline 271 & $\mathrm{H}_{3}^{+}+\mathrm{H}_{2} \mathrm{O} \rightarrow \mathrm{H}_{3} \mathrm{O}^{+}+\mathrm{H}_{2}$ & $4.50 \mathrm{e}-09$ & -0.50 & 0.00 & $\bullet$ & $\bullet$ & $\bullet$ & $\bullet$ \\
\hline 276 & $\mathrm{H}_{3}^{+}+\mathrm{CH}_{4} \mathrm{O} \rightarrow \mathrm{CH}_{3}^{+}+\mathrm{H}_{2} \mathrm{O}+\mathrm{H}_{2}$ & $1.80 \mathrm{e}-09$ & -0.50 & 0.00 & & $\bullet$ & $\bullet$ & $\bullet$ \\
\hline 279 & $\mathrm{H}_{3}^{+}+\mathrm{S} \rightarrow \mathrm{HS}^{+}+\mathrm{H}_{2}$ & & & & & $\bullet$ & $\bullet$ & $\bullet$ \\
\hline 285 & $\mathrm{H}_{3}^{+}+\mathrm{SO} \rightarrow \mathrm{HSO}^{+}+\mathrm{H}_{2}$ & $8.40 \mathrm{e}-09$ & -0.50 & 0.00 & & & $\bullet$ & \\
\hline 286 & $\mathrm{H}_{3}^{+}+\mathrm{OCS} \rightarrow \mathrm{HOCS}^{+}+\mathrm{H}_{2}$ & $3.80 \mathrm{e}-09$ & -0.50 & 0.00 & $\bullet$ & $\bullet$ & $\bullet$ & $\bullet$ \\
\hline 308 & $\mathrm{He}^{+}+\mathrm{H}_{2} \mathrm{O} \rightarrow \mathrm{OH}+\mathrm{He}+\mathrm{H}^{+}$ & $1.32 \mathrm{e}-09$ & -0.50 & 0.00 & & $\bullet$ & $\bullet$ & $\bullet$ \\
\hline 310 & $\mathrm{He}^{+}+\mathrm{CO} \rightarrow \mathrm{O}+\mathrm{C}^{+}+\mathrm{He}$ & $5.50 \mathrm{e}-10$ & -0.50 & 0.00 & & $\bullet$ & $\bullet$ & $\bullet$ \\
\hline 316 & $\mathrm{He}^{+}+\mathrm{CH}_{4} \mathrm{O} \rightarrow \mathrm{CH}_{3}^{+}+\mathrm{OH}+\mathrm{He}$ & $1.70 \mathrm{e}-09$ & -0.50 & 0.00 & & & $\bullet$ & \\
\hline 333 & $\mathrm{He}^{+}+\mathrm{OCS} \rightarrow \mathrm{CS}+\mathrm{O}^{+}+\mathrm{He}$ & $8.40 \mathrm{e}-10$ & -0.50 & 0.00 & $\bullet$ & & & \\
\hline 436 & $\mathrm{CH}_{3}^{+}+\mathrm{O} \rightarrow \mathrm{HCO}^{+}+\mathrm{H}_{2}$ & $2.05 e-10$ & 0.00 & 0.00 & & & $\bullet$ & \\
\hline 437 & $\mathrm{CH}_{3}^{+}+\mathrm{O} \rightarrow \mathrm{HOC}^{+}+\mathrm{H}_{2}$ & & & & & & $\bullet$ & \\
\hline 447 & $\mathrm{CH}_{3}^{+}+\mathrm{SO} \rightarrow \mathrm{HOCS}^{+}+\mathrm{H}_{2}$ & $4.20 \mathrm{e}-09$ & -0.50 & 0.00 & & & $\bullet$ & \\
\hline 459 & $\mathrm{CH}_{4}+\mathrm{S}^{+} \rightarrow \mathrm{H}_{3} \mathrm{CS}^{+}+\mathrm{H}$ & $1.40 \mathrm{e}-10$ & 0.00 & 0.00 & & • & $\bullet$ & $\bullet$ \\
\hline 504 & $\mathrm{O}+\mathrm{HS}^{+} \rightarrow \mathrm{S}^{+}+\mathrm{OH}$ & & & & & $\bullet$ & $\bullet$ & $\bullet$ \\
\hline 505 & $\mathrm{O}+\mathrm{HS}^{+} \rightarrow \mathrm{SO}^{+}+\mathrm{H}$ & & & & & $\bullet$ & $\bullet$ & $\bullet$ \\
\hline 506 & $\mathrm{O}+\mathrm{H}_{2} \mathrm{~S}^{+} \rightarrow \mathrm{HS}^{+}+\mathrm{OH}$ & & & & & $\bullet$ & $\bullet$ & $\bullet$ \\
\hline 507 & $\mathrm{O}+\mathrm{H}_{2} \mathrm{~S}^{+} \rightarrow \mathrm{SO}^{+}+\mathrm{H}_{2}$ & & & & & $\bullet$ & $\bullet$ & $\bullet$ \\
\hline 537 & $\mathrm{H}_{2} \mathrm{O}+\mathrm{HCO}^{+} \rightarrow \mathrm{CO}+\mathrm{H}_{3} \mathrm{O}^{+}$ & $2.10 \mathrm{e}-09$ & -0.50 & 0.00 & $\bullet$ & $\bullet$ & & $\bullet$ \\
\hline 539 & $\mathrm{H}_{2} \mathrm{O}+\mathrm{HS}^{+} \rightarrow \mathrm{S}+\mathrm{H}_{3} \mathrm{O}^{+}$ & & & & & $\bullet$ & $\bullet$ & $\bullet$ \\
\hline 540 & $\mathrm{H}_{2} \mathrm{O}+\mathrm{H}_{2} \mathrm{~S}^{+} \rightarrow \mathrm{HS}+\mathrm{H}_{3} \mathrm{O}^{+}$ & $7.00 \mathrm{e}-10$ & 0.00 & 0.00 & & $\bullet$ & $\bullet$ & $\bullet$ \\
\hline 550 & $\mathrm{H}_{2} \mathrm{O}^{+}+\mathrm{H}_{2} \mathrm{~S} \rightarrow \mathrm{H}_{3} \mathrm{~S}^{+}+\mathrm{OH}$ & $7.00 \mathrm{e}-10$ & 0.00 & 0.00 & & & & $\bullet$ \\
\hline 552 & $\mathrm{H}_{3} \mathrm{O}^{+}+\mathrm{H}_{2} \mathrm{CO} \rightarrow \mathrm{H}_{3} \mathrm{CO}^{+}+\mathrm{H}_{2} \mathrm{O}$ & $2.60 \mathrm{e}-09$ & -0.50 & 0.00 & $\bullet$ & $\bullet$ & $\bullet$ & $\bullet$ \\
\hline 553 & $\mathrm{H}_{3} \mathrm{O}^{+}+\mathrm{CH}_{4} \mathrm{O} \rightarrow \mathrm{CH}_{5} \mathrm{O}^{+}+\mathrm{H}_{2} \mathrm{O}$ & & & & $\bullet$ & $\bullet$ & $\bullet$ & $\bullet$ \\
\hline 556 & $\mathrm{H}_{3} \mathrm{O}^{+}+\mathrm{H}_{2} \mathrm{~S} \rightarrow \mathrm{H}_{3} \mathrm{~S}^{+}+\mathrm{H}_{2} \mathrm{O}$ & & & & $\bullet$ & $\bullet$ & $\bullet$ & $\bullet$ \\
\hline 579 & $\mathrm{HCO}^{+}+\mathrm{OCS} \rightarrow \mathrm{HOCS}^{+}+\mathrm{CO}$ & $1.50 \mathrm{e}-09$ & -0.50 & 0.00 & $\bullet$ & $\bullet$ & & $\bullet$ \\
\hline 585 & $\mathrm{H}_{2} \mathrm{CO}+\mathrm{S}^{+} \rightarrow \mathrm{H}_{2} \mathrm{~S}^{+}+\mathrm{CO}$ & $1.10 \mathrm{e}-09$ & -0.50 & 0.00 & & $\bullet$ & $\bullet$ & $\bullet$ \\
\hline 586 & $\mathrm{H}_{2} \mathrm{CO}+\mathrm{S}^{+} \rightarrow \mathrm{HCO}^{+}+\mathrm{HS}$ & $1.10 \mathrm{e}-09$ & -0.50 & 0.00 & & $\bullet$ & $\bullet$ & $\bullet$ \\
\hline 587 & $\mathrm{H}_{2} \mathrm{CO}+\mathrm{H}_{3} \mathrm{~S}^{+} \rightarrow \mathrm{H}_{3} \mathrm{CO}^{+}+\mathrm{H}_{2} \mathrm{~S}$ & & & & $\bullet$ & $\bullet$ & $\bullet$ & \\
\hline
\end{tabular}


V. Wakelam et al.: S-molecules as chemical clocks, Online Material p 3

Table 3. continued.

\begin{tabular}{|c|c|c|c|c|c|c|c|c|}
\hline Number & Reaction $^{1}$ & $\alpha$ & $\beta$ & $\gamma$ & Mod. 1 & Mod. 2 & Mod. 3 & Mod. 4 \\
\hline 595 & $\mathrm{~S}+\mathrm{H}_{3} \mathrm{~S}^{+} \rightarrow \mathrm{H}_{2} \mathrm{~S}_{2}^{+}+\mathrm{H}$ & & & & & $\bullet$ & $\bullet$ & \\
\hline 597 & $\mathrm{~S}^{+}+\mathrm{H}_{2} \mathrm{~S} \rightarrow \mathrm{S}_{2}^{+}+\mathrm{H}_{2}$ & $6.40 \mathrm{e}-10$ & -0.50 & 0.00 & & $\bullet$ & $\bullet$ & \\
\hline 603 & $\mathrm{H}_{2} \mathrm{~S}+\mathrm{SO}^{+} \rightarrow \mathrm{S}_{2}^{+}+\mathrm{H}_{2} \mathrm{O}$ & $1.10 \mathrm{e}-09$ & 0.00 & 0.00 & & $\bullet$ & • & • \\
\hline 614 & $\mathrm{H}^{+}+\mathrm{H}_{2} \mathrm{O} \rightarrow \mathrm{H}_{2} \mathrm{O}^{+}+\mathrm{H}$ & $7.30 \mathrm{e}-09$ & -0.50 & 0.00 & & & $\bullet$ & \\
\hline 624 & $\mathrm{H}^{+}+\mathrm{SO} \rightarrow \mathrm{SO}^{+}+\mathrm{H}$ & $1.40 \mathrm{e}-08$ & -0.50 & 0.00 & & & $\bullet$ & \\
\hline 739 & $\mathrm{~S}+\mathrm{HS}^{+} \rightarrow \mathrm{HS}+\mathrm{S}^{+}$ & & & & & • & & • \\
\hline 740 & $\mathrm{~S}+\mathrm{H}_{2} \mathrm{~S}^{+} \rightarrow \mathrm{H}_{2} \mathrm{~S}+\mathrm{S}^{+}$ & & & & & - & - & - \\
\hline 751 & $\mathrm{H}_{2}+\mathrm{CH}_{3}^{+} \rightarrow \mathrm{CH}_{5}^{+}+$PHOTON & & & & & & • & \\
\hline 756 & $\mathrm{O}+\mathrm{SO} \rightarrow \mathrm{SO}_{2}+$ PHOTON & $3.20 \mathrm{e}-16$ & -1.60 & 0.00 & $\bullet$ & $\bullet$ & $\bullet$ & $\bullet$ \\
\hline 757 & $\mathrm{CO}+\mathrm{S} \rightarrow \mathrm{OCS}+\mathrm{PHOTON}$ & & & & $\bullet$ & $\bullet$ & $\bullet$ & $\bullet$ \\
\hline 789 & $\mathrm{H}_{3} \mathrm{O}^{+}+\mathrm{e}^{-} \rightarrow \mathrm{OH}+\mathrm{H}+\mathrm{H}$ & & & & & • & & • \\
\hline 798 & $\mathrm{H}_{3} \mathrm{CO}^{+}+\mathrm{e}^{-} \rightarrow \mathrm{CO}+\mathrm{H}+\mathrm{H}_{2}$ & & & & & - & - & - \\
\hline 799 & $\mathrm{H}_{3} \mathrm{CO}^{+}+\mathrm{e}^{-} \rightarrow \mathrm{HCO}+\mathrm{H}+\mathrm{H}$ & & & & & • & • & • \\
\hline 800 & $\mathrm{H}_{3} \mathrm{CO}^{+}+\mathrm{e}^{-} \rightarrow \mathrm{H}_{2} \mathrm{CO}+\mathrm{H}$ & & & & & $\bullet$ & & • \\
\hline 803 & $\mathrm{CH}_{5} \mathrm{O}^{+}+\mathrm{e}^{-} \rightarrow \mathrm{CH}_{4} \mathrm{O}+\mathrm{H}$ & & & & & $\bullet$ & $\bullet$ & \\
\hline 804 & $\mathrm{CH}_{5} \mathrm{O}^{+}+\mathrm{e}^{-} \rightarrow \mathrm{H}_{2} \mathrm{CO}+\mathrm{H}_{2}+\mathrm{H}$ & & & & & $\bullet$ & • & \\
\hline 812 & $\mathrm{H}_{3} \mathrm{~S}^{+}+\mathrm{e}^{-} \rightarrow \mathrm{HS}+\mathrm{H}+\mathrm{H}$ & $1.00 \mathrm{e}-07$ & -0.50 & 0.00 & - & & & \\
\hline 818 & $\mathrm{H}_{3} \mathrm{CS}^{+}+\mathrm{e}^{-} \rightarrow \mathrm{CS}+\mathrm{H}_{2}+\mathrm{H}$ & & & & & $\bullet$ & & $\bullet$ \\
\hline 819 & $\mathrm{H}_{3} \mathrm{CS}^{+}+\mathrm{e}^{-} \rightarrow \mathrm{H}_{2} \mathrm{CS}+\mathrm{H}$ & & & & & • & & • \\
\hline 820 & $\mathrm{SO}^{+}+\mathrm{e}^{-} \rightarrow \mathrm{S}+\mathrm{O}$ & & & & & - & - & • \\
\hline 821 & $\mathrm{HSO}^{+}+\mathrm{e}^{-} \rightarrow \mathrm{SO}+\mathrm{H}$ & & & & & & - & \\
\hline 822 & $\mathrm{OCS}^{+}+\mathrm{e}^{-} \rightarrow \mathrm{CO}+\mathrm{S}$ & $3.00 \mathrm{e}-07$ & 0.00 & 0.00 & & • & • & • \\
\hline 823 & $\mathrm{OCS}^{+}+\mathrm{e}^{-} \rightarrow \mathrm{CS}+\mathrm{O}$ & & & & & - & - & • \\
\hline 824 & $\mathrm{HOCS}^{+}+\mathrm{e}^{-} \rightarrow \mathrm{CS}+\mathrm{OH}$ & & & & - & - & - & • \\
\hline 825 & $\mathrm{HOCS}^{+}+\mathrm{e}^{-} \rightarrow \mathrm{OCS}+\mathrm{H}$ & & & & • & $\bullet$ & $\bullet$ & • \\
\hline
\end{tabular}

${ }^{1}$ Only rate coefficients that differ by more than 10 percent from the UMIST value are included. 
V. Wakelam et al.: S-molecules as chemical clocks, Online Material $p 4$

Table 4. Additional important reactions for a perturbation amplitude of 1.0, for model 2 and Composition A.

\begin{tabular}{l|l|rrr}
\hline \hline Number & Reaction $^{a}$ & $\alpha$ & $\beta$ & $\gamma$ \\
\hline 168 & $\mathrm{C}+\mathrm{SO}_{2} \rightarrow \mathrm{CO}+\mathrm{SO}$ & $1.20 \mathrm{e}-10$ & 0.00 & 0.00 \\
173 & $\mathrm{CH}_{2}+\mathrm{O} \rightarrow \mathrm{CO}+\mathrm{H}+\mathrm{H}$ & $1.32 \mathrm{e}-09$ & -0.50 & 0.00 \\
308 & $\mathrm{He}^{+}+\mathrm{H}_{2} \mathrm{O} \rightarrow \mathrm{OH}+\mathrm{He}+\mathrm{H}^{+}$ & $1.32 \mathrm{e}-09$ & -0.50 & 0.00 \\
309 & $\mathrm{He}^{+}+\mathrm{H}_{2} \mathrm{O} \rightarrow \mathrm{OH}^{+}+\mathrm{He}+\mathrm{H}$ & $8.40 \mathrm{e}-10$ & -0.50 & 0.00 \\
333 & $\mathrm{He}^{+}+\mathrm{OCS} \rightarrow \mathrm{CS}^{+} \mathrm{O}^{+}+\mathrm{He}$ & $1.80 \mathrm{e}-09$ & -0.50 & 0.00 \\
360 & $\mathrm{C}^{+}+\mathrm{H}_{2} \mathrm{O} \rightarrow \mathrm{HOC}^{+}+\mathrm{H}$ & & & \\
444 & $\mathrm{CH}_{3}^{+}+\mathrm{S} \rightarrow \mathrm{HCS}^{+}+\mathrm{H}_{2}$ & $4.20 \mathrm{e}-09$ & -0.50 & 0.00 \\
447 & $\mathrm{CH}_{3}^{+}+\mathrm{SO} \rightarrow \mathrm{HOCS}^{+}+\mathrm{H}_{2}$ & $1.40 \mathrm{e}-10$ & 0.00 & 0.00 \\
459 & $\mathrm{CH}_{4}+\mathrm{S}^{+} \rightarrow \mathrm{H}_{3} \mathrm{CS}^{+}+\mathrm{H}$ & $5.00 \mathrm{e}-10$ & 0.00 & 0.00 \\
509 & $\mathrm{O}+\mathrm{HCS}^{+} \rightarrow \mathrm{S}+\mathrm{HCO}^{+}$ & $5.00 \mathrm{e}-10$ & 0.00 & 0.00 \\
510 & $\mathrm{O}+\mathrm{HCS}^{+} \rightarrow \mathrm{OCS}^{+}+\mathrm{H}$ & $2.60 \mathrm{e}-09$ & -0.50 & 0.00 \\
552 & $\mathrm{H}_{3} \mathrm{O}^{+}+\mathrm{H}_{2} \mathrm{CO} \rightarrow \mathrm{H}_{3} \mathrm{CO}^{+}+\mathrm{H}_{2} \mathrm{O}$ & & \\
553 & $\mathrm{H}_{3} \mathrm{O}^{+}+\mathrm{CH}_{4} \mathrm{O} \rightarrow \mathrm{CH}_{5} \mathrm{O}^{+}+\mathrm{H}_{2} \mathrm{O}$ & & & \\
646 & $\mathrm{He}^{+}+\mathrm{H}_{2} \mathrm{O} \rightarrow \mathrm{H}_{2} \mathrm{O}^{+}+\mathrm{He}$ & $1.32 \mathrm{e}-09$ & -0.50 & 0.00 \\
663 & $\mathrm{C}^{+}+\mathrm{S} \rightarrow \mathrm{S}^{+}+\mathrm{C}$ & & & \\
\hline
\end{tabular}

${ }^{a}$ Only rate coefficients that differ by more than 10 percent from the UMIST value are included. 
Table 5. Additional important reactions at $200 \mathrm{~K}$, for model 2 and Composition A.

\begin{tabular}{|c|c|c|c|c|}
\hline Number & Reaction $^{a}$ & $\alpha$ & $\beta$ & $\gamma$ \\
\hline 107 & $\mathrm{CO}+\mathrm{CRPHOT} \rightarrow \mathrm{O}+\mathrm{C}$ & $1.30 \mathrm{e}-16$ & 0.00 & 0.00 \\
\hline 125 & $\mathrm{SO}+\mathrm{CRPHOT} \rightarrow \mathrm{SO}^{+}+\mathrm{e}^{-}$ & $1.30 \mathrm{e}-14$ & 0.00 & 0.00 \\
\hline 153 & $\mathrm{H}_{2}+\mathrm{O} \rightarrow \mathrm{OH}+\mathrm{H}$ & & & \\
\hline 154 & $\mathrm{H}_{2}+\mathrm{OH} \rightarrow \mathrm{H}_{2} \mathrm{O}+\mathrm{H}$ & $8.40 \mathrm{e}-13$ & 0.00 & 1040 \\
\hline 166 & $\mathrm{C}+\mathrm{SO} \rightarrow \mathrm{S}+\mathrm{CO}$ & $3.50 \mathrm{e}-11$ & 0.00 & 0 \\
\hline 173 & $\mathrm{CH}_{2}+\mathrm{O} \rightarrow \mathrm{CO}+\mathrm{H}+\mathrm{H}$ & $1.20 \mathrm{e}-10$ & 0.00 & 0 \\
\hline 186 & $\mathrm{O}+\mathrm{OH} \rightarrow \mathrm{O}_{2}+\mathrm{H}$ & & & \\
\hline 190 & $\mathrm{O}+\mathrm{H}_{2} \mathrm{~S} \rightarrow \mathrm{HS}+\mathrm{OH}$ & $9.22 \mathrm{e}-12$ & 0.00 & 1800 \\
\hline 204 & $\mathrm{OH}+\mathrm{SO} \rightarrow \mathrm{SO}_{2}+\mathrm{H}$ & & & \\
\hline 309 & $\mathrm{He}^{+}+\mathrm{H}_{2} \mathrm{O} \rightarrow \mathrm{OH}^{+}+\mathrm{He}+\mathrm{H}$ & $1.32 \mathrm{e}-09$ & -0.50 & 0.00 \\
\hline 360 & $\mathrm{C}^{+}+\mathrm{H}_{2} \mathrm{O} \rightarrow \mathrm{HOC}^{+}+\mathrm{H}$ & $1.80 \mathrm{e}-09$ & -0.50 & 0.00 \\
\hline 436 & $\mathrm{CH}_{3}^{+}+\mathrm{O} \rightarrow \mathrm{HCO}^{+}+\mathrm{H}_{2}$ & $2.05 \mathrm{e}-10$ & 0.00 & 0.00 \\
\hline 437 & $\mathrm{CH}_{3}^{+}+\mathrm{O} \rightarrow \mathrm{HOC}^{+}+\mathrm{H}_{2}$ & & & \\
\hline 646 & $\mathrm{He}^{+}+\mathrm{H}_{2} \mathrm{O} \rightarrow \mathrm{H}_{2} \mathrm{O}^{+}+\mathrm{He}$ & $1.32 \mathrm{e}-09$ & -0.50 & 0.00 \\
\hline 663 & $\mathrm{C}^{+}+\mathrm{S} \rightarrow \mathrm{S}^{+}+\mathrm{C}$ & & & \\
\hline
\end{tabular}

${ }^{a}$ Only rate coefficients that differ by more than 10 percent from the UMIST value are included.
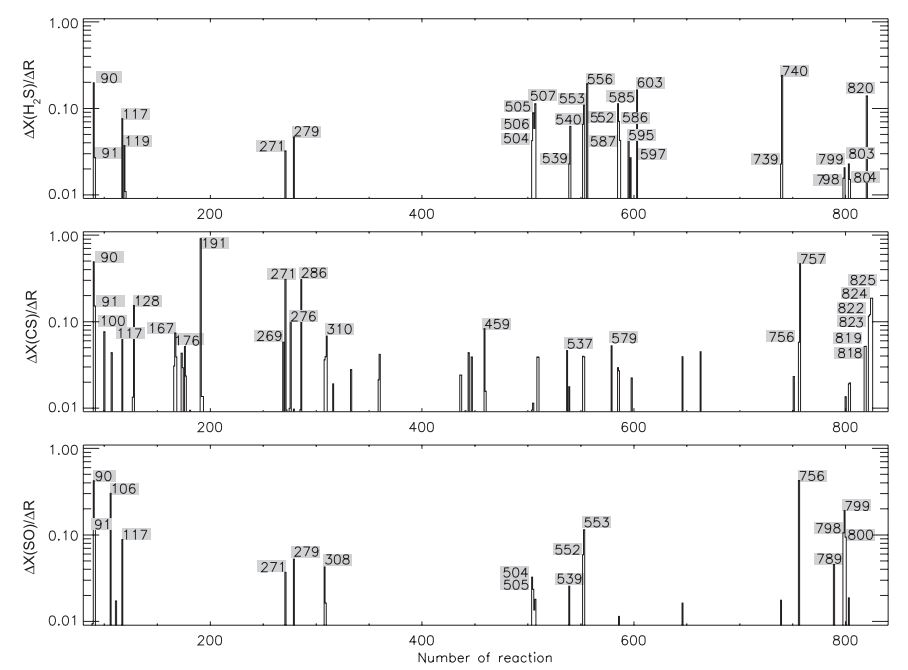

Fig. 1. The "variation" $\Delta X$ (see text) of the abundances of $\mathrm{SO}, \mathrm{H}_{2} \mathrm{~S}$, and CS divided by the amplitude $(\Delta R=0.1)$ of the perturbation of the rate coefficients plotted for reactions with number between 86 and 834 ; i.e., all the reactions in the model exept those dealing with dust grains. The numbers indicate those reactions that induce a variation of more than $5 \%$ of the highest variation for each species. 